\title{
Ecological model of the Bay of Biscay and English Channel shelf for Environmental Status assessment Part 1: Nutrients, phytoplankton and oxygen
}

\author{
Ménesguen Alain ${ }^{1,{ }^{*}}$, Dussauze Morgan ${ }^{2}$, Dumas Franck ${ }^{3}$, Thouvenin Benedicte ${ }^{1}$, Garnier Valerie ${ }^{4}$, \\ Lecornu Fabrice ${ }^{1}$, Répécaud Michel ${ }^{5}$
}

${ }^{1}$ Ifremer/Centre de Brest, Unité ODE/DYNECO, B.P.70, 29280 Plouzané, France

${ }^{2}$ Actimar, 36 Quai de la Douane, 29200 Brest, France

${ }^{3} \mathrm{SHOM} / \mathrm{DOPS} / \mathrm{HOM} / \mathrm{REC}, 13$ rue du Chatellier, CS 92803, 29228 Brest cedex 2, France

${ }^{4}$ Ifremer/Centre de Brest, Unité ODE/LOPS, B.P.70, 29280 Plouzané, France

${ }^{5}$ Ifremer/Centre de Brest, Unité REM/RDT, B.P.70, 29280 Plouzané, France

* Corresponding author : Alain Ménesguen, email address : amenesg@ifremer.fr

\begin{abstract}
:
European directives (Water Framework Directive - WFD and Marine Strategy Framework Directive MSFD) require a regular survey of several descriptors of the Environmental Status of coastal waters of the North-east Atlantic Ocean. Especially for the MSFD, which may concern large continental shelf areas where measurements are scarce, realistic ecological models can help assessing the Environmental Status. The ECO-MARS3D model of the pelagic ecosystem of the Bay of Biscay and English Channel continental shelf (NE Atlantic) has been developed for these applied purposes and validated against various types of historic data. This first paper deals with the basic biogeochemical version, which contains inorganic nutrients $(\mathrm{NH} 4, \mathrm{NO} 3, \mathrm{PO} 4, \mathrm{Si}(\mathrm{OH}) 4)$, three phytoplankton bulk types (diatoms, nanoflagellates and dinoflagellates), two zooplankton bulk types, particulate detrital forms and dissolved oxygen. A second paper presents a version of this model including 3 harmful phytoplanktonic groups. A simulation covering the 2000-2010 decade is compared to satellite sea surface data for temperature and surface chlorophyll, to the Southampton-Bilbao and Ouistreham-Portsmouth ferrybox surface data for temperature, salinity, chlorophyll and nutrients, to point samples provided by the French network of phytoplankton monitoring (REPHY) for inorganic nutrients and chlorophyll, and to high frequency time series of dissolved oxygen measured by a moored automatic buoy. From a spatial point of view, the model provides realistic fields of annual means of surface temperature (but with a systematic bias of about $+1.0^{\circ} \mathrm{C}$ ) and phytoplanktonic biomass. From a seasonal point of view, the temperature and salinity follow correctly the observed variations. For nutrient and total chlorophyll, the model succeeds in reproducing the difference amounting to one order of magnitude between the North Sea coastal zones and the oligotrophic oceanic zone above the abyssal plain of the bay of Biscay. It also reproduces the spring-neap tide oscillation visible in satellite observations of surface chlorophyll. Simulated seasonal cycles are realistic in the coastal stations, but the French Atlantic coast seems slightly too nutrient-rich. In coastal eutrophicated areas, the model does not produce chlorophyll peaks as high as measured. In the Vilaine bay (France), the summer hypoxic conditions (down to $4 \mathrm{mg} / \mathrm{L} \mathrm{O2}$ or less) are correctly reproduced. This ecological model has been used off-line to map some classical eutrophication descriptors (winter DIN and DIP, March-October 90th percentile of chlorophyll) used by
\end{abstract}


the WFD and MSFD European directives. It has also been turned into an operational real-time mode, as part of the French Previmer project (now: http://marc.ifremer.fr/resultats/production primaire).

\section{Highlights}

ECO-MARS3D model is described for the French continental shelf pelagic ecosystem. It provides descriptors for the WFD and MSFD assessment of eutrophication status. Validation is made on the 2000-2010 decade for descriptors used in WFD and MSFD. Maps showing the areas not in Good Ecological Status for the descriptors are provided. A running operational application of this model provides $\mathrm{N}$-tracking from 3 rivers.

Keywords: Ecological 3D model, Continental shelf, Bay of Biscay and English Channel, Surface chlorophyll, Dissolved oxygen, MSFD 


\section{Introduction}

The European Water and Marine Strategy Framework Directives have put forward the mandatory assessment of the Environmental Status of coastal marine waters. Whereas the Water Framework Directive (WFD, Directive 2000/60/EC) remains in the one nautical mile strip along the coast, the Marine Strategy Framework Directive (MSFD, Directive 2008/56/EC) encompasses wide areas on the N-W European shelf, up to the 200 nautical miles wide Exclusive Economic Zone of each country. Whereas the WFD/water masses can be frequently surveyed by numerous very coastal sampling stations, MSFD subregions lack sampling in many parts. The high cost of repetitive monitoring campaigns with medium size vessels able to cover the whole 200 nautical miles wide domain has led to alternative monitoring strategies, including field measurements coming from buoys or ferryboxes, and remote sensing from satellites. The latter now provide repetitive (daily) and reliable surface maps of temperature, inorganic suspended matter and total chlorophyll content (Gohin et al., 2005), the storage of which has progressively build a valuable archive (http://doi.org/10.12770/9352f74a-7ecb-485e-8ea3-9aa91001b9a1) for annual assessment of some descriptors required by the European Directives.

The numerical models have been used for years to complement this surface view of the ocean by giving a three-dimensional picture. For practical reasons however (run-time and memory size available, uncertainty about the mathematical formulation of some processes), they remain limited with many respects by some simplifications they are based on (e.g. mixing by internal waves not taken into account).

Concerning the hydrodynamics of the area here under consideration (the English Channel and the Bay of Biscay), the following points are noticeable:

- Even if confined in the temperate zone, the north-western European continental shelf spans a large latitudinal area (from $43^{\circ} \mathrm{N}$ to $53^{\circ} \mathrm{N}$ ) and consequently a wide range of meteorological drivers that varyingly force the biology. The most obvious example of this latitudinal variability is linked to the North Atlantic Oscillation 
between the Icelandic low and the Azores high pressures, as exhibited by Cassou et al. (2004).

- The domain extends from the coast to the open ocean. It thus encompasses on the one hand areas directly under the continental influence (large runoffs), with very shallow waters clearly in highly frictional regimes and on the other hand deeper ocean closer to the geostrophic equilibrium (Yankovsky, 2006, Hill et al., 2008) showing strong seasonal haline and thermal stratifications (Puillat et al., 2004). The fast moving limits between the two may coincide with thermal fronts (e.g. Le Boyer et al., 2009) or external limits of fully mixed plumes (e.g. the Seine plume in the English Channel, Cugier and Le Hir, 2002)

- Two contrasting regions coexist within the domain. Salomon and Breton (1993) showed that the English Channel is dynamically dominated by the barotropic tide, which generates high vertical mixing by the frictional effects. On the contrary, the bay of Biscay, largely open, shows weak tidal currents, except close to the coast around capes (Le Cann 1990). This allows a haline stratification to establish in plumes of significant river runoffs (Lazure and Jegou 1998), along with a strong summer thermal stratification offshore. These pycnoclines may be affected by large internal waves even very close to the coast (Lazure et al. 2014).

This variety of regimes and processes (Koutsikopoulos and Le Cann 1996) shapes various marine landscapes that can be described by numerical models, as evidenced by Planque et al. (2004). Those models in return can provide 3D pictures of several WFD/MSFD descriptors which remain inaccessible (nutrients) or poorly documented (phytoplanktonic groups) by remote sensing. They thus provide a valuable archive for annual assessment of some descriptors required by the European Directives. Moreover, these 3D models can also be run in an operational mode and take advantage from satellite-derived maps to validate the simulated results in the surface layer (Siddorn et al., 2007, Edwards et al., 2012, Wan et al., 2012). 
From a biogeochemical point of view, this rather small region has the advantage of displaying very different marine pelagic ecosystems, going from an oceanic, deep part in the south-western bay of Biscay with oligotrophic surface waters, to the very landinfluenced, shallow coastal areas of the English Channel, with eutrophic waters in the river plumes. The nutrient richness can then be two orders of magnitude greater in some coastal waters than in the oceanic ones (Loyer et al., 2006).

This paper presents a validation of the ECO-MARS3D biogeochemical model, which has been developed in order to assess some WFD/MSFD eutrophication descriptors (nitrate, phosphate, total chlorophyll, dissolved oxygen) along the French Atlantic-Channel coast, and currently used for testing nutrient reduction scenarios (Ménesguen et al., 2018a, Desmit et al., 2018) or assessing the part of nitrogen loadings of the most important rivers of that region in the phytoplankton biomass composition) (Ménesguen et al., 2018b, Lacroix et al., 2015).

A real-time version of this model has beén running operationally since 2007 (2007 to 2015: http://www.previmer.org/previsions/production_primaire, since 2016: $\underline{\text { http://marc.ifremer.fr/resultats/production_primaire) }}$ and is briefly presented at the end of the paper. 


\section{Methods}

\subsection{Model characteristics}

This ECO-MARS3D ecological model is based on the MARS3D hydrodynamical code (Lazure and Dumas, 2008). The current application to the French Atlantic shelf is based on a regular grid with $4 \times 4 \mathrm{~km}$ meshes and 30 sigma layers, which covers the Bay of Biscay, the English Channel and the southern part of the North Sea, up to the Rhine estuary. The domain extends from $8.13^{\circ} \mathrm{W}$ to $5.0^{\circ} \mathrm{E}$, and from $43.17^{\circ} \mathrm{N}$ to $52.75^{\circ} \mathrm{N}$ (Fig.1).

Mechanical forcing is provided by the barotropic sea-level oscillation at the oceanic boundaries (previously computed by a 2D model covering the whole North-East Atlantic), and wind and atmospheric pressure at the sea surface, which come from the Arpege system of Météo-France with a $30 \mathrm{~km}$ and $6 \mathrm{~h}$ space-time resolution. Measured daily discharges as well as monthly river temperatures are provided on line by the Seine-Normandy, Loire-Brittany and Adour-Garonne River Basin Agencies, for the five main French rivers: Adour, Gironde, Loire, Vilaine, Seine. For all the other rivers in the domain, only discrete measurements of flow rates made in recent years are available, and interpolated for the hindcast runs. In operational mode, the daily flow rate of these rivers is deduced from the measured flow rate of the nearest main river by linear regression. River daily concentrations for inorganic and organic dissolved nutrients are computed from empirical statistical relationships involving flow rate and time fitted to historical data (Guillaud and Bouriel, 2007). Suspended particulate matter is set to the maximum of ambient climatological monthly mean distribution derived from satellite data (Gohin et al., 2005) and the simulated turbid plumes of the rivers, which are simply computed by considering river loads of suspended matter as a particulate conservative tracer, having a uniform and constant settling velocity. At the open boundaries, a zero gradient condition is imposed to all the dissolved and particulate state variables.

The basic biogeochemical model (Fig.2) has been built to gain some insight into the strong phytoplanktonic blooms characteristic of some eutrophicated river plumes (Seine, 
Vilaine and Loire) in the area under concern. Some dinoflagellates are known to be responsible for various coloured waters in summer (Guillaud and Ménesguen, 1998), which can lead to severe bottom hypoxia or anoxia, as in July 1982 in the bay of Vilaine (Chapelle et al., 1994). Some other dinoflagellates produce toxins which hamper the bivalve fishery (Reguera et al., 2014). In order to bring a first approach of some summer harmful effects, when low silicate concentrations depress the diatom populations, our model must at least simulate the silicified part of the phytoplankton (diatoms) separately from the non-silicified part. Among the non-silicified species, dinoflagellates are not always the dominant group in terms of biomass. For instance, the Bay of Biscay exhibits also blooms of coccolithophoridae (free motile nanoflagellates), especially along the edge of the continental slope (Lampert et al., 2002) and on the thermal front crossing the western entrance of the English Channel in summer. The Eastern English Channel and the Southern North Sea have also shown recurring high blooms of the colonial nanoflagellate Phaeocystis globosa (Lancelot et al., 1987). So, two non-silicified groups have been simulated separately, the so-called dinoflagellates and nanoflagellates. In the eastern English Channel and the southern North Sea, the excess of nitrate after spring depletion of silicate and phosphate is known to have triggered eutrophication (Lancelot et al., 2007). In the Loire plume in the bay of Biscay, the summer abundance of ammonia has enhanced dinoflagellate blooms (Sournia et al., 1992, Sourisseau et al., 2016). In order to assess the respective roles of the nitrogenous and phosphorous terrestrial loadings in these very highly productive areas, inorganic and detrital organic forms of N, P and Si have been explicitly simulated, because they are driven by very different remineralisation rates. However, for the sake of simplicity and run-time efficiency in the perspective of decadal runs, and because individual cell $\mathrm{N}$ or $\mathrm{P}$ content may be very different among the species gathered into the three bulk groups, a quota formulation of phytoplankton growth has not been implemented for the three bulk phytoplanktonic groups. The quota formulation will be reserved for the 3 harmful phytoplankton genus or species treated in the second paper. So, the basic living state variables (phytoplankton and zooplankton) have been 
only simulated in nitrogen currency and linked to phosphorus and silicon compartments by simple stoichiometric ratios. As it appears important to take into account the photoacclimation in waters of very different mean turbidity present in such a vast and heterogeneous domain, the chlorophyll content of each phytoplanktonic group is deduced from the corresponding nitrogenous state variable of the model by a locally defined Chl:N ratio. In order to avoid daily integration of light intensity at every depth, and chaotic daily variations of computed chlorophyll between cloudy and sunny days, we have computed the Chl:N ratio from a slow-varying proxy of the local light availability, i.e. the local extinction coefficient, which is itself computed from suspended particulate inorganic material and chlorophyll at the previous time step. The relationship used is a hyperbola-like Smith's function (Smith, 1936). Finally, this bloom-oriented ecological model contains 17 state variables (see Table I). Corresponding equations are given in Appendix A, and the parameter values used in the model are given in Table II. These equations describe the biological cycles of the main limiting elements and the dissolved oxygen in the water column, coupled to bulk detrital benthic compartments. Three limiting dissolved inorganic nutrients are considered: nitrogen, with ammonium (Eq. 1) and nitrate (Eq. 2) separately, silicon (Eq. 3), and phosphorus (Eq. 4). The phosphorus temporary adsorbed on suspended particles is computed following Eq. 5. The microzooplankton (Eq. 9) eats diatoms, nanoflagellates and detrital particulate matter, whereas the mesozooplankton (Eq. 10) eats diatoms, dinoflagellates and microzooplankton. So, in this model, diatoms (Eq. 6) do sink, whereas dinoflagellates (Eq. 7) and nanoflagellates (Eq. 8) do not (they are considered as able to maintain at any depth in calm water, thanks to motility). Three particulate detrital variables, detrital N (Eq. 11), detrital biogenic Si (Eq. 12) and detrital P (Eq. 13), close the biogeochemical cycles. They settle in the water column. In the bottom layer, owing to a deposition velocity linked to ambient current velocity (see Appendix B), each settling fraction is partially transferred to a corresponding immobile, benthic state variable. This last one can give back to the water layer some particulate material through erosion by currents (see erosion rate in Appendix B), and 
the dissolved equivalent produced by benthic remineralisation (see Eq. 14, 15 and 16). The benthic filtration is taken into account only in the bottom water layer, as a filtration rate per surface unit, modulated in time by a sine function with a one year period and in space by the turbidity (see Appendix B). The sine amplitude decreases linearly when turbidity increases (see Appendix B), in order to mimic the decrease of filter feeders abundance in turbid waters. The oxygen budget (Eq. 17) is constructed assuming the following stoichiometric equation of primary production:

$106 \mathrm{CO}_{2}+16 \mathrm{HNO}_{3}+\mathrm{H}_{3} \mathrm{PO}_{4}+122 \mathrm{H}_{2} \mathrm{O} \rightarrow \mathrm{C}_{106} \mathrm{H}_{263} \mathrm{O}_{110} \mathrm{~N}_{16} \mathrm{P}+138 \mathrm{O}_{2}$

Such a model with compartments having mean residence times of several months and distributed over a rather big area may exhibit long lasting transitory regimes. As far as advective transport through the domain is concerned, the mapping of the mean age of nitrogen tracked since its delivery by the Loire river, as provided by the operational version of this model, has shown that residual transport from the mid bay of Biscay up to the southern North Sea takes about two years and a half. Regarding the benthic storing compartment, intense resuspension during winter and exponential decay by burial allows reaching a stabilized annual cycle of distributed benthic compartments after one year. So, in order to get rid of the unrealistic, uniform initial yalues, the year 2000 was first spun-up two times, before doing the real run from January 1, 2000 until December 31, 2010. This 11 years simulation has been done without any assimilation or any variable re-initialisation.

\subsection{Monitoring network data}

Numerous data have been gathered for validation purposes. They come mainly from REPHY (REseau d'observation et de surveillance du PHYtoplancton et des phycotoxines), MAREL (Mesures Automatisées en Réseau pour l'Environnement et le Littoral) and SOMLIT (Service d'Observation en Milieu Littoral) monitoring networks for the French coastal zone, from CEFAS (Centre for Environment, Fisheries and Aquaculture Science) and WCO (Western Channel Observatory) for the U.K coastal zone (Fig.1), from the BMDC (Belgian 
Marine Data Center) for the Belgian coastal zone. For this study, we have extracted from these databases time-series of surface measurements of dissolved nutrients $\left(\mathrm{NO}_{3}, \mathrm{PO}_{4}\right.$, $\left.\mathrm{Si}(\mathrm{OH})_{4}\right)$, total chlorophyll along with salinity and temperature. The temperature profiles at station E1 near Plymouth have been measured by a SeaBird SBE19+ probe, as described in Smyth et al. (2010), and downloaded from WCO website. A unique time-series of dissolved oxygen in surface and bottom waters has been measured in the bay of Vilaine by the MAREL buoy named "MOLIT". Seawater is pumped every 30 minutes one meter below the surface and one meter above the bottom and analysed following the method described in Blain et al. (2004).

\subsubsection{Ferrybox data}

The area covered by the model is currently sampled by several ferryboxes. Here, we will only refer to published data, i.e. the 2010 results obtained by Napoleon et al. (2012) on the M.V. Normandie (Brittany ferries) on a $175 \mathrm{~km}$ transect between Ouistreham (France) and Portsmouth (U.K), and Smythe-Wright et al. (2014) on the M.V. Pride of Bilbao (P\&O ferries) on a $1000 \mathrm{~km}$ transect between Portsmouth (UK) and Bilbao (Spain).

\subsubsection{Satellite data}

NOAA AVHRR measurements of Sea Surface Temperature and MODIS colour measurements are collected by Ifremer's Nausicaa browser automat, with a subsequent merging of images collected during the 4 last days, in order to partially fill the holes caused by cloud covering. The MODIS images of sea surface chlorophyll are obtained from 5 band reflectance ratios provided by the satellite thanks to the OC5 algorithm (Gohin et al., 2002), which has been recognised as the most efficient for coastal waters in West-European waters (Tilstone et al., 2017).

\subsection{Method of comparison between simulations and observations}

Validation of a 3D, multivariate ecological model is not a straightforward task, for 3 reasons at least: $1 /$ very few state variables of the model are measured in the field: here, we have only some measurements for temperature, salinity, inorganic nutrients and chlorophyll 
concentration, 2/ measurements are not made on a complete 4D grid (latitude $\mathrm{x}$ longitude $\mathrm{x}$ depth $\mathrm{x}$ time), 3/ exact matching in space and time for biological variables (e.g. chlorophyll) which have a behaviour more bursty than smooth and continuous is highly unlikely: Lacroix et al. (2007) has shown that the correlation between measured and predicted time-series is often poor in a precise location (e.g. $\mathrm{R}^{2}=0.44$ for chlorophyll at the Belgian 330 station), but can even worsen when computed on time- or space-distributed values (e.g. $R^{2}=0.20$ for chlorophyll at all the model meshes during the spring period March-April-May). In order to explore various time- and space scales, the validation process has been made in 4 steps:

1/ a purely spatial comparison for 3 descriptors, in order to test the global ability of the model to reproduce the great geographical patterns over the Bay of Biscay and the English Channel. For sea surface temperature (SST), the simulated decadal mean has been compared to the satellite-derived decadal average map, whereas for sea surface chlorophyll (SSC), the decadal $90^{\text {th }}$ percentile computed over the productive period (March to October) has been retained and computed for simulated and satellite-derived data, as more relevant for Environmental Status assessment.

2/ a time series comparison between the daily simulated and satellite-derived SST (resp. SSC), averaged over 4 specific bathymetric strata, which have been empirically delineated according to the observed decadal distribution of SSC. Based on the highest SSC values, a first coastal strip under the influence of all the tributaries has been defined between the 0 and $25 \mathrm{~m}$ isobaths. A second one, more off-shore and ending approximatively near the $40 \mathrm{~m}$ isobath, still exhibits medium SSC values, and stays under the influence of medium and large river plumes. The rest of the continental shelf is less productive and is covered by the 40$200 \mathrm{~m}$ bathymetric range, whereas poor oceanic waters are gathered in the fourth bathymetric stratum, ranging from 200 to $6000 \mathrm{~m}$ depths.

3/ a surface transect comparison with 2 published data series collected by ferryboxes aboard ships of opportunity. 
4/ a point comparison of simulated temperature, salinity, nutrients and chlorophyll at six coastal stations.

The tools used for quantitative comparison are the scatterplot simulation vs. observation and the Taylor's diagram.

\subsection{Environmental Status assessment}

In accordance with the Convention for the Protection of the Marine Environment of the North-East Atlantic (OSPAR Commission, 2003), some indicators which are currently used to describe marine eutrophication can be computed from our model. Our model can provide indicators in the four categories of qualitative assessment criteria listed in the Comprehensive Procedure: nitrate and phosphate January-February winter) mean (Category I: Nutrient enrichment), $90^{\text {th }}$ percentile of total surface chlorophyll during the March-October productive period (Category II: Direct effects of nutrient enrichment), $10^{\text {th }}$ percentile of bottom dissolved oxygen during the March-October productive period (Category III: Indirect effects of nutrient enrichment) and $90^{\text {th }}$ percentile of surface Dinoflagellate/Diatom ratio during the March-October productive period (Category IV: Other effects of nutrient enrichment). As far as the European Directives (WFD and MSFD) are concerned, these maps may be used to assess the coastal areas which are actually beyond the corresponding thresholds of Good Environmental Status (GES). 


\section{Results}

The hindcasting 2000-2010 period offers the opportunity of providing high river discharges during rainy years (2000, 2001 and 2008) contrasting with low freshwater inputs during dry years (2005 and 2009), the years 2004 and 2007 being intermediate (Table 3). 2003 has also a medium freshwater input, but with a very hot summer. The operational application has then been done since the January 1, 2012.

\subsection{Validation hindcasts}

\subsubsection{Mean spatial distribution}

From a global point of view, the model reproduces the main characteristics of the SST and chlorophyll geographical distribution. The measured mean decadal SST (Fig.3) decreases regularly over a $2.5^{\circ} \mathrm{C}$ range from south Biscay to the English Channel entrance, and again over another $2^{\circ} \mathrm{C}$ range from the English Channel entrance to the southern North Sea. This north-south gradient, as well as the warm spot in the south-eastern corner, are qualitatively well reproduced in size and location, but the cold anomaly along the north-western coast of the French Brittany peninsula is not so acute in the model as in the observations. Globally speaking, the model shows a hot bias varying from 0.5 to $1{ }^{\circ} \mathrm{C}$ across the whole domain. The simulated decadal distribution $90^{\text {th }}$ percentile of surface chlorophyll concentration (Fig.4 left) also reproduces the great difference between the poor oceanic zones located over the abyssal plain, on the outer shelf or in the western English Channel, and the productive French coastal strip of the Bay of Biscay and the eastern English Channel (enriched by the nutrient loadings of Gironde, Loire, Vilaine and Seine rivers). Scatter-plots (Fig.5) of the same data clearly show a bias in SST model (simulated SST is between $0.9^{\circ} \mathrm{C}$ and $0.5^{\circ} \mathrm{C}$ too high when the observed mean temperature goes from $11^{\circ} \mathrm{C}$ to $16^{\circ} \mathrm{C}$ ), but a rather good proportionality to observed SST (regression slope equal to 0.92). For chlorophyll, the model has a slight tendency to overestimate oceanic low values and underestimate the coastal very high values (regression slope equal 
to 0.91 ). But the main drawback regarding our assessment purposes is that the scatterplot shows a greater dispersion than for temperature, increasing with the mean value, so that individual simulated values may strongly depart from measured ones, especially in meshes very close to the coast having high observed chlorophyll content. For benthic detrital compartments, measurements of organic nitrogen or phosphorus in surface sediments are too scarce to build any map.

\subsubsection{Mean time course}

As far as the mean time course over bathymetric strata is considered, SST and SSC behave differently. The seasonal cycle of the Sea Surface Temperature (Fig.6) exhibits a sine-shaped in the four bathymetric strata $(0-25 \mathrm{~m}, 25-40 \mathrm{~m}, 40-200 \mathrm{~m}$ and $>200 \mathrm{~m})$, with the same phase but with different amplitudes. In the remotely sensed data as well as in the simulations, the annual amplitude decreases when góing from the coastal strip (observed amplitude: 10 to $13.5^{\circ} \mathrm{C}$, simulated amplitude: 11.5 to $15^{\circ} \mathrm{C}$ ) to the oceanic deep area (observed amplitude: 8 to $10^{\circ} \mathrm{C}$, simulated amplitude: 5.5 to $8.5^{\circ} \mathrm{C}$ ), but in the oceanic domain, the model produces winter minima regularly $1.5^{\circ} \mathrm{C}$ too hot. In very shallow waters (0-25m stratum), autumn and winter temperatures are correctly simulated, whereas an excessive warming occurs in spring and summer, especially since 2005.

On the contrary, the shape of the seasonal time-course, as well as the mean level, of Sea Surface Chlorophyll depends first on the bathymetric stratum, and partially on the wet/dry character of the year (Fig.7). In the $0-25 \mathrm{~m}$ strip, the spring dominant bloom is followed by a cascade of lower summer blooms fueled by river loadings and partially grazed by zooplankton, whereas more offshore, after the main peak of biomass in spring and before a small one in autumn, the summer period is poor because of its strong $\mathrm{N}$ limitation. The model succeeds in reproducing this difference in bloom phenology, as well as in providing the observed descent of mean chlorophyll level from the coast to the open ocean. The spring-neap tide fortnightly oscillation of phytoplanktonic biomass observed in satellite data is also present in the model results, But the model fails to simulate 
exceptional blooms occurring some years (2001, 2007, 2008, 2010) in late April or early May in the two shallow strata $(0-25 \mathrm{~m}$ and $25-40 \mathrm{~m})$. These exceptional high spring chlorophyll concentrations are due to blooms of Phaeocystis colonies, escaping partially to grazing and occurring mainly in the North-East part of the domain, i.e. in the shallow Eastern English Channel and in the southern North Sea, especially during "wet years" (as 2001). In the oceanic bathymetric stratum, the model reproduces in due time the spring bloom (eventually splitted into two consecutives blooms as in 2000), but maintains a summer chlorophyll two times higher than observed.

\subsubsection{Transect comparison}

Hovmöller diagrams (time along abscissa, latitude along ordinate) provide a qualitative tool for matching model and in situ data along tracks, here along the Southampton-Bilbao track (Fig.8) and the Ouistreham-Porthmouth track (Fig.9). For temperature along both tracks, a very good correspondence is found. For salinity, the correspondence is good along the Ouistreham-Porthmouth track (Fig.9), but along the Southampton-Bilbao track (Fig.8), the presence of brackish water recorded in the Southampton waters is not reproduced in the model because of the omission of Test and Itchen rivers. The impact of Loire discharge in late June is also clearly underestimated by the model. For chlorophyll, the Southampton-Bilbao track (Fig.8) shows that the model correctly reproduces the solitary, short spring bloom in the oceanic part of the Bay of Biscay, along with its gradual setup from south to north. The contrast with the longlasting chlorophyll abundance in the Western Channel (between $49^{\circ}$ and $50^{\circ} \mathrm{N}$ ) is also well reproduced by the model. On the contrary, along the Ouistreham-Porthmouth track in the Eastern Channel (Fig.9), the spring bloom appears one month earlier in ferrybox data than in the model, and more asymmetrically between the French and the U.K. sides. The simulated persistence of medium chlorophyll concentrations near Portsmouth during autumn (green color in the top right part of the model chlorophyll diagram in Fig.9) is totally absent in the ferrybox data (blue color in this part of the ferrybox diagram). For 
nitrate, phosphate and silicate in surface waters, the model provides also realistic timespace patterns, but over-estimates the winter richness in phosphate and silicate, and during summer in the Western Channel (Fig. 8 between $49^{\circ}$ and $50^{\circ} \mathrm{N}$ ).

\subsubsection{Station comparison}

Temperature is well simulated in vertically mixed coastal stations (Fig.10), even for the inter-annual anomalies (e.g. the warmer winters in January-February 2007 and 2008). In thermally stratified deeper stations, as the E1 station managed by the Plymouth Marine Laboratory at the entrance of the English Channel, south from Plymouth (Fig.11), the model provides a realistic simulation of surface temperature as well as thermocline depth (except for the June 6, 2008 situation) but regularly shows bottom waters too hot by 0.5 up to $1.5^{\circ} \mathrm{C}$.

For salinity (Fig.S_1), the model overestimates a little the differences between spring and neap tides, due to insufficient mixing and a too strong haline stratification during neap tides, especially in the bay of Vilaine.

For nutrients, the model reproduces the winter replenishment, followed by spring depletion and summer quasi-exhaustion. Nitrate (Fig.12) is correctly reproduced at different stations of the Eastern Channel, Western Channel and Bay of Biscay, but in Plymouth in the 2001-2002 winter, the model does not reproduce the exceptionally low measured values of nitrate, which indicates that this open sea station was free of strong terrestrial influence during that winter. Conversely, the model overestimates nitrate during winter and early spring at the Arcachon station. For phosphate (Fig.S_2), the model reproduces rather well the observed seasonal cycle and its mean level at the different stations, except in Arcachon station, where winter stocks are often twofold higher than in the field. Silicate (Fig.S_3) is correctly reproduced, but the model does not account for the exceptional high concentrations measured at Plymouth L4 station in autumn 2003, 2004, 2005. 
For chlorophyll (Fig.13), the model reproduces the spring bloom at the right time in 4 stations (too late in Loscolo), but underestimates the peak of biomass, especially at the Belgian station 330 near the Scheldt estuary and at Arcachon station. In the bay of Seine (Luc-sur-mer station), the model provides several blooms in summer, often not appearing in the field measurements, but frequently visible in the satellite data.

For dissolved oxygen, the only high frequency measurements available in surface as well as in bottom water layers along the Atlantic French coast are provided by the MOLIT buoy in the Vilaine bay. This location has been chosen because the only anoxia episode known along the French coasts has been registered there in July 1982 (Chapelle et al., 1994). The data collected in 2008 and 2009 (Fig.14) show several over-saturation episodes in the surface layer, caused during spring and summer by the successive blooms, and oxygen depletion episodes in the bottom layer, occurring mainly around neap tides. In 2008 and 2009, stratification of the water column has caused a pronounced hypoxia of the bottom water, due to dark respiration of the abundant phytoplankton and mineralization of the settling organic matter accompanying each bloom in the surface layer. Over the productive period (April to October), the measurements in the surface layer clearly show a day-night oscillation (24 hours period, see Fig.S_4), with a maximum of dissolved oxygen at 4 p.m. in the surface layer, i.e. after the most photosynthetically efficient hours and the daily minimum at the end of the night (6 a.m.). The same oscillation is not apparent in the bottom layer. The model correctly reproduces this daily periodicity in the surface layer, due to the light-dependance of algal photosynthesis, and its absence in the bottom layer.

The Taylor's diagrams at the six stations (Fig.15) give correlation coefficients between 0.92 and .98 for temperature, between 0.3 and 0.7 for salinity, between 0.5 and 0.8 for nitrate, 0.3 and 0.7 for silicate, 0.4 and 0.7 for phosphate (with too low a standard deviation in the Belgian station 330, and too high in the Arcachon and Loscolo stations). For chlorophyll, the correlation remains between 0.0 and 0.4 at the six stations (with too weak standard deviations in the eutrophicated stations 330 and Loscolo), but improves up 
to 0.7 when bathymetric strata are considered, and even higher (more than 0.9 , but with too big a standard deviation) when only the decadal $90^{\text {th }}$ percentile is looked at. For dissolved oxygen, the Taylor's diagram shows that the bottom simulation is correctly correlated (0.75) with the measurements during the two years 2008 and 2009, and exhibits a similar variance, but that the surface simulation is weakly correlated $(0.35)$ with the measurements, and strongly less variable, because the model does not reproduce short and very acute peaks of surface chlorophyll and the oversaturation they induce.

\subsection{Environmental Status assessment}

Simulating a decade allows building some global maps, which can help in localizing some hot points relatively to eutrophication and its remediation. As thresholds are not universal but fixed by every country, we illustrate here only the "French point of view" applied to the French MFSD sub-regions, using the following threshold values of MSFD GES (which corresponds to the limit between the second level-Good-and the third one Moderate- in the WFD Environmental Status scale): $30 \mu \mathrm{mol} / \mathrm{L}$ DIN, $2 \mu \mathrm{mol} / \mathrm{L} \mathrm{DIP,} 10$ $\mu \mathrm{g} / \mathrm{L}$ Chl.a, $2 \mathrm{mg} / \mathrm{L} \mathrm{O}_{2}$. According to these thresholds, considered as independent of salinity (see discussion), only the meshes which are not in GES have been figured in colors on Fig. 16. Their numbers over the whole domain are respectively: 1531 for the DIN descriptor, 335 for DIP and 213 for Chl.a. As far as only the French MFSD subregions (see Fig.1) are considered (i.e. $148584 \times 4 \mathrm{~km}$ meshes), the numbers of not-in-GES meshes are respectively 838 for the DIN descriptor (i.e. $13408 \mathrm{~km}^{2}$ representing $5.6 \%$ of the total area), 188 for DIP (i.e. $3008 \mathrm{~km}^{2}$ representing $1.3 \%$ of the total area), 57 for Chl.a (i.e. $912 \mathrm{~km}^{2}$ representing $0.4 \%$ of the total area). The fact that the coastal enrichment has the same riverine origin for DIN and DIP, but with a much stronger intensity for DIN, explains that all the meshes which are not in GES for DIP are simultaneously not in GES for DIN. In the same way, being not in GES for Chl.a implies being simultaneously not in GES for DIN and DIP. Comparison with assessments deduced from observations is impossible, except for surface chlorophyll. Performing the same 
delineation of meshes above the GES threshold over the full map of satellite-derived $90^{\text {th }}$ percentiles reveals that 225 meshes over the whole domain exhibit an observed $90^{\text {th }}$ percentile above $10 \mu \mathrm{g} / \mathrm{L}$ Chl.a, which is similar to the 213 ones deduced from the model. Over the sole MSFD French sub-regions however, the model underestimates the non-inGES area (57 meshes only vs. 152 in satellite observations). Both maps point to wellknown eutrophicated areas in river plumes (Rhine, Scheldt, Somme, Seine and Vilaine plumes). The main quantitative discrepancies are to be found near the northern boundary (Rhine and Thames plumes), but also in the French bay of Somme (along the French coast of the Eastern Channel). From a global point of view, these various descriptor maps show that the winter DIN concentration is by far the most deteriorated indicator, and on the most extended area. The strongly non-linear link between a single nutrient and the biomass produced is illustrated by the number of meshes not in GES for chlorophyll, which is much lower than for DIN or DIP.

The computed map of bottom dissolved oxygen $10^{\text {th }}$ percentile during the MarchOctober period (Fig.S_5) shows that the intense tidal stirring maintains a bottom oxygen concentration above $6 \mathrm{mg} / \mathrm{L}$ in the English Channel. On the contrary, the western, summer stratified part of the continental shelf shows signs of recurring hypoxia: the southern coasts of Ireland and Cornwall, the Vilaine bay, but also the silty area (the so-called "Grande vasière") extending south of Brittany towards the Gironde estuary. No mesh has a computed $10^{\text {th }}$ percentile of bottom oxygen below the GES threshold. The hypoxia simulated south from the Gironde estuary, along the Landes coast (inside the white polygon on Fig. S_5), seems however too severe and unrealistic, because no kills of marine animals by asphyxia have ever been recorded in that area. This narrow continental shelf exhibits a strong summer thermocline, which deprives the bottom layer from oxygen renewal. In the model, detrital matter accumulates in the bottom layer (see discussion) and its decomposition induces a strong consumption of dissolved oxygen.

\subsection{Operational nowcast website}


After a 2 year spin-up phase (2010 year looping on itself), the validated model is now applied in an operational mode, since January 1, 2011. Daily computed maps are available on the following web site:

http://marc.ifremer.fr/resultats/production_primaire/modele_eco_mars3d_manche_gascogne

Figure S_6 gives the look of the web site front-page. A menu gives access to simulated variables: temperature and salinity, dissolved oxygen, inorganic nutrients $\left(\mathrm{NO}_{3}, \mathrm{PO}_{4}\right.$, $\mathrm{Si}(\mathrm{OH})_{4}$ ), three bulk groups of phytoplankton (diatoms, nanoflagellates and dinoflagellates) and one harmful species, Phaeocystis globosa (detailed in a second paper), together with the corresponding simulated total chlorophyll concentration. This menu contains also the driving variable "Suspended Particulate Inorganic Matter", and the SST and Surface Chlorophyll maps remotely sensed by satellites. At every date, a pop-up window facility allows a first qualitative visual assessment of the fit between satellite measurements and simulations of SST and total chlorophyll content of the sea surface layer. A calendar tool allows screening any past day from the archive, and animations of a 12, 24 or 48 day long sequence can be launched.

The most original product of this website is the daily mapping of the influence of the three main western rivers of France (Seine, Loire, Gironde) on the marine phytoplankton. Numerical tracking (Ménesguen et al., 2006) of nitrogen brought by these rivers shows that the phytoplanktonic biomass entering the southern North Sea in the French half of the Straits of Dover contains nitrogen stemming from the Seine river to around $20 \%$ in winter and $40 \%$ in summer, from the Loire river to around $5 \%$ and from the Gironde river to around $1.5 \%$. The site gives also the mean age of this nitrogen, i.e. the mean time elapsed since the release of nitrogen by the river into the sea. For the Seine river, the age of nitrogen in the French half of the Straits of Dover amounts to 1 year in summer, 1.25 year in winter, whereas it reaches 2.75 years for the Loire river and 3 years for the Gironde river. These results substantiate the long range action of big rivers, in space as well as in 
time, and should be kept in mind when results are expected from eutrophication remediation plans.

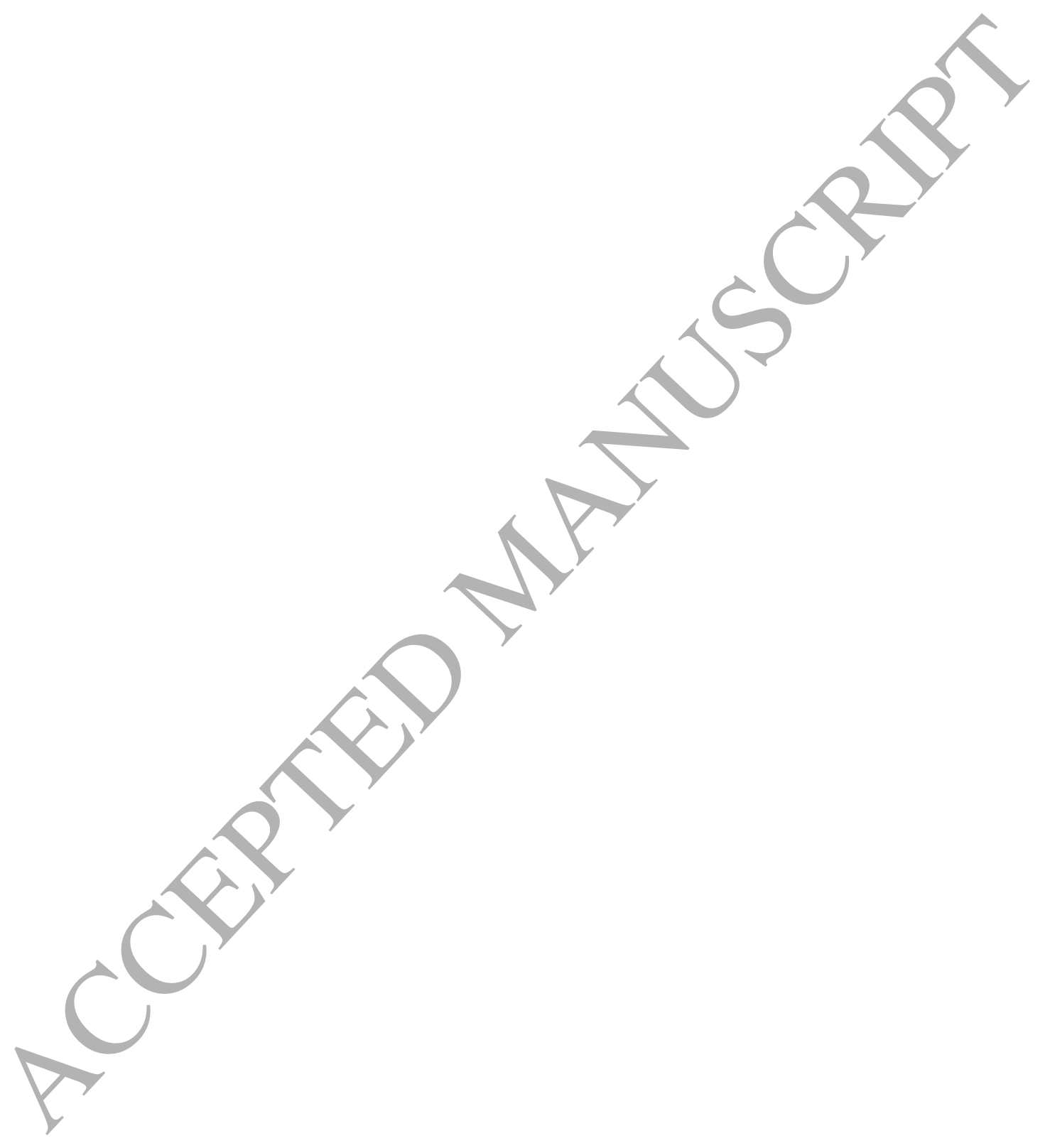




\section{Discussion}

Several 3D biogeochemical models of the North-West European shelf have been published, one using a long off-line run (1972-2008) on the sole Bay of Biscay for an environmental approach of pelagic fish fluctuations (Huret et al., 2013), but most of them dealing with a few year hindcast (Schrum et al., 2006; Skogen and Mathisen, 2009; Lenhart et al. 2010; Ford et al., 2017), some of them focusing on future climatic scenarios (Skogen et al., 2014; Wakelin et al., 2015) and only a few of them being used in an operational mode to provide every day on the web some information about current descriptors of the pelagic primary production (Allen et al., 2008). The OPEC European project, running from 2012 to 2014 (http://marineopec.eu), provided a unique portal gathering six different models dedicated to four European regional seas (North-East Atlantic, Baltic, Mediterranean and Black Seas). Daily maps can be loaded from the early 90 's up to the end of the project, mixing hindcasts and forecasts as in our Previmer site.

Arhonditsis and Brett (2004) had found that, before 2002, too few models provided some measure of goodness of fit, and recommended a strong effort in assessment of model reliability. So, this paper is a first trial to apply some standard methods (Doney et al., 2009) of assessment to a 3D ecological model of the French Atlantic shelf, and to take advantage of decadal series of fine-resolved satellite scenes of temperature and chlorophyll now available, which can greatly improye the validation accuracy, compared to the previous comparisons of models with maps interpolated from scarce field observations (e.g. Schrum et al., 2006). We retrieve some/general features also shown by other models dealing with the North-West European shelf. Almost all the models cited before point out the decrease of model accuracy when going from physical (e.g. temperature, salinity) to nutrients and then phytoplankton. In the models applied to the North Sea first by Allen et al. (2007), then by Ford et al. (2017), the linear correlation between measurements and simulations falls, in POLCOMS-ERSEM model, from 0.95 for temperature to 0.8 for salinity, to 0.6 for nutrients and to 0.4 for chlorophyll, and in NEMO-ERSEM or GETM-ERSEM-BFM models from 0.8-0.99 for sea 
surface temperature to $0.1-0.6$ for sea surface chlorophyll, which is similar to the performances of our ECO-MARS3D model previously detailed. In terms of simulated variance also, ecological models show a decrease of accuracy when moving from temperature to chlorophyll. Their low-pass filter behaviour succeeds better in simulating the small fluctuations around the annual sine function characteristic of the temperature than the sudden and short bursts of phytoplankton characteristic of the blooms. For temperature, Allen et al. (2007) found a quasi-null bias in a two-year run over the whole North Sea, whatever the depth, whereas our model shows a positive bias $\left(1^{\circ} \mathrm{C}\right)$ for the surface temperature in a tenyear run over the whole Bay of Biscay-English Channel region. As far as the thermic stratification is concerned, our model shows, at the L4 station in the English Channel, the same tendency (but in a less extent, $2^{\circ} \mathrm{C}$ instead of $5{ }^{\circ} \mathrm{C}$ ) to overestimate the bottom temperature as the GETM-ERSEM-BFM model (van Leeuwen et al., 2015) in the Oyster Grounds $\left(54.4^{\circ} \mathrm{N}, 4.02^{\circ} \mathrm{E}\right)$. But for chlorophyll, the POLCOMS-ERSEM model showed negative bias, i.e. a constant underestimation of phytoplanktonic biomass, whereas our model shows almost no bias for the surface chlorophyll, but a clear underestimation of variance. In the Baltic Sea, Wan et al. (2012) found that the surface temperature and salinity seasonal dynamics were very well simulated $\left(r \geq 0.97\right.$ ), but with a positive bias (up to $2^{\circ} \mathrm{C}$ for summer temperature in some places), as in our model. For their biogeochemical variables, on the contrary, the correlation between surface simulations and measurements dropped to values even lower than in our model ( $\mathrm{r}=0.3$ for DIN, $\mathrm{r}=0.24$ for chlorophyll) and the relative bias increased (up to $58 \%$ for DIN). The bottom dissolved oxygen appears to be the most difficult to be correctly simulated by this Baltic Sea model, especially in the deep quasi-anoxic trenches. Our model is applied to a macrotidal and open coastal sea, where no severe and long-lasting hypoxia is to be found, but only summer moderate and pulsed hypoxia events in some stratified areas. At our unique station of high frequency measurement, our model shows rather good a simulation of bottom hypoxia, but fails at producing strong summer oversaturations in the surface layer, because blooms simulated in the surface layer during summer 
are not acute enough to produce intense bursts of dissolved oxygen. The unrealistic strong hypoxia simulated on the sandy continental shelf located in front of the southern French Biscayan coast, south from Gironde estuary (Fig. S_5), may be due to insufficient simulated bottom erosion caused by the lack of internal tides in this large mesh size $(4 \mathrm{x} 4 \mathrm{~km})$ grid. Mooring measurements (Le Boyer et al 2013, Kersalé et al 2016) have proved that the Landes continental shelf exhibits strong coastal tidal currents in summer, resulting from internal tide propagation (Lazure et al., 2014). These baroclinic tidal currents disappear when the stratification breaks down in autumn, and measured tidal currents then go back to weak, purely barotropic, values, the only ones which are simulated by our ECO-MARS3D model.

The 3D ecological models have been rarely used for mapping synthetic descriptors related to eutrophication, except for the Baltic Sea (Almroth and Skogen, 2010; Skogen et al., 2012; Savchuk et al., 2014). In their review of ecological models able to provide information about indicators outlined in the Marine Strategy Framework Directive, Piroddi et al. (2015) found 26 models potentially useful for eutrophication indicators. But very few of them have really performed long simulations (at least 6 years to cope with the cyclic assessment rounds of the MSFD) and have computed synthetic descriptor maps. For the Baltic Sea, Almroth and Skogen (2010) combined the maps provided by four models for various descriptors (DIN, DIP, DIN:DIP ratio, chlorophyll, bottom oxygen), weighted by their fitness to the corresponding fields of discrete observations, in order to build a continuous best estimate of the eutrophication status. The simulated maps of indicators presented here have been used in a similar way in conjunction with neighbour models (MOHID and MIRO\&Co) sharing some common zones, as part of the European EMOSEM project (Lacroix et al., 2016). A methodological problem however arises concerning mean winter nutrients. The thresholds proposed in OSPAR and MSFD assessment procedures are given at a reference salinity (e.g. 33 for France, 33.5 for Belgium) and field measurements of DIN or DIP have to be projected to the reference salinity, owing to the local linear relation between these nutrients and salinity drawn from the whole set of measurements. In the case of an extended domain as ours, no 
unique empirical relationship arises from couples of simulated salinities and nutrients: a scatterplot (Fig. S_7) shows several linear clouds, each of them corresponding to the plume of one major tributary to the marine domain. Due to the indecision about which relation has to be chosen, especially in areas of overlapping plumes, no variation of nutrient thresholds with salinity has been taken into account in our global assessment from the model. For "extreme value" descriptors like chlorophyll $90^{\text {th }}$ percentile and dissolved oxygen $10^{\text {th }}$ percentile, the methodological problem arising from use of a model is different. Thanks to the complete cover of satellite-derived observations of surface chlorophyll, this work illustrates on the example of chlorophyll the difficulty to obtain reliable simulated "extreme" values at the right location, because a model acts as a low-pass filter in many cases (Ménesguen et al., 2007). Undoubtly, this fact diminishes the power of the models in assessing the most interesting synthetic descriptors related to eutrophication, which target the damageable extreme situations.

As far as models are to be used in an operational mode, reliability is a highly desirable property, which should be assessed in real-time by comparison to synchronous field measurements. Unfortunately, apart from satellite maps of observed temperature and chlorophyll, field measurements are very scarce and rarely available in real-time, and no field data is available for several state variables of ecological models. On the North-West Atlantic shelf, some time- or space high resolution measured time-series are already available either at fixed stations (buoys) or along tracks (ferryboxes, gliders, AUVs), and it is hoped that they will gradually improve the validation process. However, methodology for automatic detection of shift in time or space domain between model and observations needs to be improved. Some tools have been proposed, for computing at various resolutions different components of agreement and disagreement between simulated and observed maps (Pontius et al., 2004). Rerunning the model for hindcasting the past situation with more realistic forcing (river flow rates and nutrient concentrations, meteorological drivers) when they become available could 
also improve the reliability of the final archive produced by the operational application; this is not planned in our case.

Another question is how to provide in real-time mode a confidence interval around the predictions. Monte-Carlo techniques to construct time- and space varying sensitivity of the main state variables to equation parameters, boundary conditions, or meteorological and river forcing, can be used off-line, but are too time-consuming to be run on-line with 3D ecological models that get tens of state variables. Rather than spending time to assess the uncertainty of the existing model, it seems more appropriate to look at the weak points which can be rapidly corrected. For instance, in this model, boundary values are defined from climatological atlases, and of course the next step is to feed this coastal model with real time boundary conditions provided by an OGCM such as Mercator Ocean Model, as it is already done in the UK operational model NEMO-ERSEM, at least for elevations, currents, temperature and salinity (Siddorn et al., 2007). Another critical point for primary production models is the way they take into account the exchange of particles and solutes between the water column and the sediment. In our model, we have used a simple formulation very similar to that adopted by Eilola et al. (2009) for their model of the Baltic Sea, without explicit discretisation of the sediment into layers. Introducing layers of mixed sediments (silt and sand) would allow a deterministic simulation of sediment resuspension by waves and currents as well as nutrient exchange between the sediments and the bottom waters. If this may improve the computed extinction coefficient as well as the available nutrients in shallow areas, it adds numerous supplementary parameters, the calibration of which requires measured profiles of biogeochemical state variables, and increases dramatically the computing time. Such a detailed approach has been very uncommon and limited to tiny 3D grids (Sohma et al., 2008), but a simplified model for SPM resuspension has been recently tested on a large grid covering the northwest European continental shelf (van der Molen et al., 2017). 
Regarding the operational use of ecological models, which is still in the beginning, we must better define the final products that users really need. The main information currently available on operational web sites is dedicated to mapping classical state variables describing the actual state of some major characteristics of the ecosystem. But the interest of people in such websites would be greatly enhanced if additional diagnostic variables could be proposed, which would provide a real-time explanation of some puzzling phenomena observed. For instance, pointing out the main cause of a sudden phytoplankton bloom should be very informative: was it due to a sudden increase of a growth factor (light increase, nutrient increased availability, from which origin?) or a sudden decrease of a decay factor (lower predation, diminished settling rate)? The website presented here tracks only three possible river sources of nitrogen in algal compartments. Adding more potential sources would provide a better causative explanation to the sudden massive blooms of diatoms or dinoflagellates, and help pointing out the rivers in which lowering the nutrient loading (especially nitrogen) has priority.

\section{Conclusion}

An ecological model of the phytoplankton covering the Bay of Biscay/English Channel shelf has been compared on a ten-year period to various data (remotely sensed images of SST and surface chlorophyll, samples from monitoring stations, data from a buoy), in order to use it for assessing several status indicators of marine eutrophication required by the European directives (WFD or MSFD) or convention (OSPAR), Globally speaking, the model was able to reproduce the geographical pattern as well as the seasonal mean time course of nutrients and total chlorophyll. It reproduces also the occurrence of strong hypoxia events in the bottom layer of the bay of Vilaine, as observed by an automatic buoy. However, introducing a more realistic sediment erosion and near bottom mixing remains necessary for a realistic bottom oxygen simulation in the southern part of the Bay of Biscay continental shelf. Since the beginning of 2011, this model has been turned into 
an operational mode, to provide daily maps on the web for various basic geochemical descriptors, over a large part of the Ireland-Biscay-Iberia Regional Operational Oceanographic System domain (IBI-ROOS). This operational tool will over the years provide a growing collection of daily simulated situations, which will be used to build a statistical description of the "mean" nutrient and phytoplanktonic annual cycle in these coastal areas, as well as to define what can be designated as being "extreme" events. This information will feed the Water Frame Directive report for the French water masses, and will help to assess the Environmental Status of the French sub-regions defined in the Marine Strategy Frame Directive. In order to get into a more detailed assessment of that Environmental Status, a second paper will be devoted to the simulation of three added harmful phytoplankton groups (Karenia, Phaeocystis and Pseudo-nitzschia), competing with the bulk types of phytoplankton, but having noxious effects either on the marine life or on the human consumer health. 


\section{Acknowledgements}

We are indebted to Francis Gohin (Ifremer/Brest) and Philippe Bryère (ACRI/Brest) for having provided the numerous, daily interpolated, satellite images of Sea Surface Temperature and Chlorophyll. We thank also Jean-François Le Roux and Jacques Legrand (Ifremer/Brest) for helping to the management of the operational website (formerly www.previmer.org, now marc.ifremer.fr), and Lucia Pineau-Guillou and Sébastien Theeten for monitoring the daily operational process. This work has been funded partially by the Region Bretagne. 


\section{Tables}

Table 1. List of the biogeochemical state variables.

\begin{tabular}{|c|c|c|}
\hline Symbol & Meaning & Unit \\
\hline $\mathrm{X}_{1}$ & Ammonium & $\mu \operatorname{molN~L}{ }^{-1}$ \\
\hline $\mathrm{X}_{2}$ & Nitrate & $\mu \mathrm{molN} \mathrm{L}{ }^{-1}$ \\
\hline $\mathrm{X}_{3}$ & Dissolved silicon & $\mu \mathrm{molSi} \mathrm{L}-1$ \\
\hline $\mathrm{X}_{4}$ & Dissolved phosphorus & $\mu$ molP L \\
\hline $\mathrm{X}_{5}$ & Particulate exchangeable phosphorus & \\
\hline $\mathrm{X}_{6}$ & Diatom nitrogen & $\mu \mathrm{molN} \mathrm{Lj}{ }^{-1}$ \\
\hline $\mathrm{X}_{7}$ & Dinoflagellate nitrogen & $\mu \mathrm{molN} \mathrm{L}{ }^{-1}$ \\
\hline $\mathrm{X}_{8}$ & Nanoflagellate nitrogen & $\mu \operatorname{molN~L}{ }^{-1}$ \\
\hline $\mathrm{X}_{9}$ & Microzooplankton nitrogen & $\mu \operatorname{molN~L}{ }^{-1}$ \\
\hline $\mathrm{X}_{10}$ & Mesozooplankton nitrogen & $\mu \mathrm{molN} \mathrm{L}{ }^{-1}$ \\
\hline $\mathrm{X}_{11}$ & Suspended detrital organic nitrogen & $\mu \operatorname{molN~L}{ }^{-1}$ \\
\hline $\mathrm{X}_{12}$ & Suspended detrital biogenic silicon & $\mu \mathrm{molSi} \mathrm{L}^{-1}$ \\
\hline $\mathrm{X}_{13}$ & Suspended detrital organic phosphorus & $\mu \mathrm{molP} \mathrm{L}{ }^{-1}$ \\
\hline $\mathrm{X}_{14}$ & Benthic detrital organic nitrogen & $\mathrm{mmolN} \mathrm{m}^{-2}$ \\
\hline $\mathrm{X}_{15}$ & Benthic detrital biogenic silicon & $\mathrm{mmolSi} \mathrm{m}^{-2}$ \\
\hline $\mathrm{X}_{16}$ & Benthic detrital organic phosphorus & $\mathrm{mmolP} \mathrm{m}^{-2}$ \\
\hline $\mathrm{X}_{17}$ & Dissolved oxygen & $\mathrm{mgO} \mathrm{L}^{-1}$ \\
\hline
\end{tabular}


Table 2. Parameters of the biogeochemical model

\begin{tabular}{|c|c|c|c|}
\hline Symbol & Meaning & Unit & Value \\
\hline \multicolumn{4}{|c|}{ Phytoplancton (general) } \\
\hline $\mathrm{r}_{\mathrm{O} 2: \mathrm{N} \_ \text {ana }}$ & $\mathrm{O}_{2}: \mathrm{N}$ ratio for photosynthesis & $\mathrm{mg} \mu \mathrm{mol}^{-1}$ & 0.260 \\
\hline $\mathrm{r}_{\mathrm{O} 2: \mathrm{N} \_c a t a}$ & $\mathrm{O}_{2}: \mathrm{N}$ ratio for respiration &  & 0.212 \\
\hline$r_{P: N}$ & P:N ratio & $\mathrm{mol} \mathrm{mol}^{-1}$ & 0.067 \\
\hline $\mathrm{r}_{\mathrm{N} \text { :chloro }}$ & $\mathrm{N}$ :chlorophyll $a$ ratio & $\mathrm{mol} \mathrm{g}^{-1}$ & [0.4-1.4] \\
\hline $\mathrm{r}_{\text {respphy }}$ & Respiration rate at $0^{\circ} \mathrm{C}$ in the dark & $\mathrm{d}^{-1}$ & 0.03 \\
\hline \multicolumn{4}{|l|}{ Diatoms } \\
\hline$\mu_{\text {maxdiat }}$ & Maximum growth rate at $0^{\circ} \mathrm{C}$ & $\mathrm{d}^{-1}$ & 0.65 \\
\hline $\mathrm{I}_{\text {kdiat }}$ & Smith light intensity parameter & $\mathrm{W} \mathrm{m}^{-2}$ & 60 \\
\hline $\mathrm{K}_{\mathrm{NH} 4 \mathrm{diat}}$ & Half saturation constant for $\mathrm{NH}_{4}$ & $\mu \mathrm{mol} \mathrm{L}-1$ & \\
\hline $\mathrm{K}_{\mathrm{NO} \text { diat }}$ & Half saturation constant for $\mathrm{NO}_{3}$ & $\mu \mathrm{mol} \mathrm{L}-1$ & 1.5 \\
\hline $\mathrm{K}_{\text {Sidiat }}$ & Half saturation constant for $\mathrm{Si}$ & $\mu \mathrm{mol} \mathrm{L} \mathrm{L}^{-1}$ & \\
\hline $\mathrm{K}_{\text {Pdiat }}$ & Half saturation constant for $\mathrm{P}$ & $\mu \mathrm{mol} \mathrm{L}{ }^{-1}$ & \\
\hline $\mathrm{V}_{\text {sdiatmin }}$ & Minimal sedimentation velocity & $\mathrm{m} \mathrm{d}^{-1}$ & 0.5 \\
\hline $\mathrm{V}_{\text {sdiatmax }}$ & Maximal sedimentation velocity & $\mathrm{m} \mathrm{d}$ & 5.0 \\
\hline $\mathrm{m}_{\text {diat }}$ & Mortality rate at $0^{\circ} \mathrm{C}$ & & 0.01 \\
\hline $\mathrm{r}_{\mathrm{Si}: \mathrm{N}}$ & $\mathrm{Si}: \mathrm{N}$ ratio & & 0.75 \\
\hline \multicolumn{4}{|l|}{ Dinoflagellates } \\
\hline$\mu_{\operatorname{maxdino}}$ & Maximum growth rate at $0^{\circ} \mathrm{C}$ & & 0.35 \\
\hline $\mathrm{I}_{\mathrm{kdino}}$ & Smith light intensity parameter & & 40 \\
\hline $\mathrm{K}_{\mathrm{NH} 4 \mathrm{dino}}$ & Half saturation constant for $\mathrm{NH}_{4}$ & $\mu \mathrm{mol} \mathrm{L} \mathrm{L}^{-1}$ & 3.0 \\
\hline $\mathrm{K}_{\mathrm{NO3dino}}$ & Half saturation constant for $\mathrm{NO}_{3}$ & $\mu \mathrm{mol} \mathrm{L}-1$ & 5.0 \\
\hline $\mathrm{K}_{\text {Pdino }}$ & Half saturation constant for $\mathrm{P}$ & $\mu \mathrm{mol} \mathrm{L}-1$ & 0.2 \\
\hline $\mathrm{m}_{\mathrm{dino}}$ & Mortality rate at $0^{\circ} \mathrm{C}$ & $d^{-1}$ & 0.02 \\
\hline \multicolumn{4}{|l|}{ Nanoflagellates } \\
\hline$\mu_{\operatorname{maxnano}}$ & Maximum growth rate at $0^{\circ} \mathrm{C}$ & $\mathrm{d}^{-1}$ & 0.8 \\
\hline $\mathrm{I}_{\mathrm{knano}}$ & Smith light intensity parameter & $\mathrm{W} \mathrm{m}^{-2}$ & 60 \\
\hline $\mathrm{K}_{\mathrm{NH} 4 \mathrm{nano}}$ & Half saturation constant for $\mathrm{NH}_{4}$ & $\mu \mathrm{mol} \mathrm{L}-1$ & 0.4 \\
\hline $\mathrm{K}_{\mathrm{NO} \text { nnano }}$ & Half saturation constant for $\mathrm{NO}_{3}$ & $\mu \mathrm{mol} \mathrm{L}-1$ & 0.2 \\
\hline $\mathrm{K}_{\text {Pnano }}$ & Half saturation constant for $\mathrm{P}$ & $\mu \mathrm{mol} \mathrm{L}-1$ & 0.05 \\
\hline $\mathrm{m}_{\text {nano }}$ & Mortality rate at $0^{\circ} \mathrm{C}$ & $\mathrm{d}^{-1}$ & 0.15 \\
\hline \multicolumn{4}{|c|}{ Zooplankton (general) } \\
\hline Ass & Assimilation & dimensionless & 0.6 \\
\hline $\mathrm{r}_{\text {respzoo }}$ & Respiration rate at $0^{\circ} \mathrm{C}$ & $d^{-1}$ & 0.08 \\
\hline \multicolumn{4}{|c|}{ Microzooplankton } \\
\hline$\mu_{\text {maxmicrozoo }}$ & Maximum growth rate at $0^{\circ} \mathrm{C}$ & $d^{-1}$ & 0.3 \\
\hline $\mathrm{K}_{\text {microzoo }}$ & Half saturation constant for predation on nitrogen & $\mu \mathrm{mol} \mathrm{L}-1$ & 0.7 \\
\hline thr $_{\text {microzoo }}$ & Nitrogen prey threshold for predation & $\mu \mathrm{mol} \mathrm{L}-1$ & 0.1 \\
\hline $\mathrm{e}_{\text {microzoo }}$ & Excretion & $d^{-1}$ & 0.1 \\
\hline $\mathrm{m}_{\text {microzoo }}$ & Mortality rate at $0^{\circ} \mathrm{C}$ & $\mathrm{d}^{-1}$ & 0.02 \\
\hline$\tau_{\text {diat_microzoo }}$ & Edibility of diatoms & dimensionless & 0.4 \\
\hline$\tau_{\text {nano_microzoo }}$ & Edibility of nanoflagellates & dimensionless & 1.0 \\
\hline$\tau_{\text {det_microzoo }}$ & Edibility of detrital matter & dimensionless & 0.8 \\
\hline \multicolumn{4}{|c|}{ Mesoozooplankton } \\
\hline$\mu_{\text {maxmesozoo }}$ & Maximum growth rate at $0^{\circ} \mathrm{C}$ & $d^{-1}$ & 0.25 \\
\hline$\gamma_{\text {mesozoo }}$ & Initial slope of Ivlev's predation function on nitrogen & $\mathrm{L} \mu \mathrm{mol}^{-1}$ & 0.2 \\
\hline thr $r_{\text {mesozoo }}$ & Nitrogen prey threshold for predation & $\mu \mathrm{mol} \mathrm{L}-1$ & 0.1 \\
\hline $\mathrm{e}_{\text {mesozoo }}$ & Excretion & $\mathrm{d}^{-1}$ & 0.03 \\
\hline $\mathrm{m} 1_{\text {mesozoo }}$ & Minimum mortality rate at $0^{\circ} \mathrm{C}$ & $\mathrm{d}^{-1}$ & 0.03 \\
\hline $\mathrm{m} 2_{\text {mesozoo }}$ & Biomass dependent mortality rate at $0^{\circ} \mathrm{C}$ & $\mathrm{d}^{-1} \mu \mathrm{mol}^{-1} \mathrm{~L}$ & 0.04 \\
\hline$\tau_{\text {diat_mesozoo }}$ & Edibility of diatoms & dimensionless & 1.0 \\
\hline$\tau_{\text {dino_mesozoo }}$ & Edibility of dinoflagellates & dimensionless & 0.1 \\
\hline$\tau_{\text {microzoo mesozoo }}$ & Edibility of microzooplankton & dimensionless & 0.5 \\
\hline
\end{tabular}




\begin{tabular}{|c|c|c|c|}
\hline \multicolumn{4}{|c|}{ Particulate adsorbed phosphorus and detrital organic matter } \\
\hline $\mathrm{k}_{\text {desorp }}$ & Phosphorus desorption rate & $\mathrm{d}^{-1}$ & 2.4 \\
\hline $\mathrm{k}_{\text {adsorp }}$ & Phosphorus adsorption rate & $\mathrm{d}^{-1} \mathrm{~L} \mu \mathrm{mol}^{-1}$ & 0.12 \\
\hline $\mathrm{Q}_{0 \max }$ & Max. P adsorption capacity (suspended matter) & $\mu \mathrm{mol} \mathrm{g}-1$ & 40 \\
\hline $\mathrm{k}_{\operatorname{minN}}$ & $\mathrm{N}$ mineralization rate at $0^{\circ} \mathrm{C}$ & $d^{-1}$ & 0.02 \\
\hline $\mathrm{k}_{\text {nitrif }}$ & Nitrification rate at $0^{\circ} \mathrm{C}$ & $d^{-1}$ & 0.06 \\
\hline $\mathrm{k}_{\min \mathrm{P}}$ & $\mathrm{P}$ mineralization rate at $0^{\circ} \mathrm{C}$ & $d^{-1}$ & 0.15 \\
\hline $\mathrm{k}_{\text {dissol }}$ & Si dissolution rate at $0^{\circ} \mathrm{C}$ & $d^{-1}$ & 0.07 \\
\hline$r_{\text {bent }}$ & Mineralization slowing factor in sediment vs water & dimensionless & 0.2 \\
\hline $\mathrm{w}_{\mathrm{s}}$ & Settling velocity of detritus in water & $\mathrm{m} \mathrm{s}^{-1}$ & 0.00001 \\
\hline $\mathrm{r}_{\text {erodref }}$ & $\begin{array}{l}\text { Rate of erosion of benthic detrital nitrogen when } \\
u=2 u_{\text {criterod }}\end{array}$ & $\mathrm{mol} \mathrm{m} \mathrm{s}^{-1}$ & 0.0001 \\
\hline $\mathrm{u}_{\text {criterod }}$ & Minimum current velocity for benthic erosion & $\mathrm{m} \mathrm{s}^{-1}$ & 0.2 \\
\hline $\mathrm{u}_{\text {critdep }}$ & Maximum current velocity for benthic deposition & $\mathrm{m} \mathrm{s}^{-1}$ & 0.3 \\
\hline $\mathrm{k}_{\mathrm{DM}}$ & Extinction coefficient due to dissolved matter & $\mathrm{m}^{-1}$ & \\
\hline $\mathrm{k}_{\mathrm{SM}}$ & Extinction coefficient for suspended matter & $\mathrm{m}^{-1} \mathrm{mg}^{-1} \mathrm{~L}$ & \\
\hline $\mathrm{k}_{\mathrm{C} 1}$ & First extinction coefficient for chlorophyll & & \\
\hline $\mathrm{k}_{\mathrm{C} 2}$ & Second extinction coefficient for chlorophyll & dimensionless & 0.75 \\
\hline
\end{tabular}


Table 3. Mean annual flow rates $\left(\mathrm{m}^{3} \mathrm{~s}^{-1}\right)$ of the main French rivers under consideration.

\begin{tabular}{|c|c|c|c|c|c|c|c|c|c|c|c|c|}
\hline & $\mathbf{2 0 0 0}$ & $\mathbf{2 0 0 1}$ & $\mathbf{2 0 0 2}$ & $\mathbf{2 0 0 3}$ & $\mathbf{2 0 0 4}$ & $\mathbf{2 0 0 5}$ & $\mathbf{2 0 0 6}$ & $\mathbf{2 0 0 7}$ & $\mathbf{2 0 0 8}$ & $\mathbf{2 0 0 9}$ & $\mathbf{2 0 1 0}$ & $\mathbf{2 0 0 0 / 2 0 1 0}$ \\
\hline GIRONDE & 999 & 979 & 695 & 808 & 913 & 544 & 689 & 739 & 932 & 799 & 722 & $\mathbf{8 0 3}$ \\
\hline LOIRE & 1169 & 1312 & 753 & 910 & 879 & 565 & 724 & 909 & 1006 & 618 & 820 & $\mathbf{8 8 1}$ \\
\hline SEINE & 737 & 914 & 637 & 439 & 418 & 343 & 461 & 503 & 521 & 329 & 408 & $\mathbf{5 1 9}$ \\
\hline
\end{tabular}




\section{References}

Allen, J.I., Holt, J.T., Blackford, J., Proctor, R., 2007. Error quantification of a high-resolution coupled hydrodynamic-ecosystem coastal-ocean model: part 2. Chlorophyll-a, nutrients and SPM. J. Mar. Syst., 68 (3-4), 381-404.

Allen J.I., Smyth T.J., Siddorn J.R., Holt M., 2008. How well can we forecast high biomass algal bloom events in a eutrophic coastal sea? Harmful Algae, 8(1), 70-76.

Almroth, E., Skogen, M.D., 2010. A North Sea and Baltic Sea Model Ensemble Eutrophication Assessment. Ambio 39, 59-69.

Arhonditsis, G.B., Brett, M.T., 2004. Evaluation of the current state of mechanistical aquatic biogeochemical modelling. Mar. Ecol. Prog. Ser. 271, 13-26.

Blain S., Guillou J., Tréguer P., Woerther P., Delauney L., Follenfant E., Gontier O., Hamon M., Leildé B., Masson A., Tartu C., Vuillemin R., 2004. High frequency monitoring of the coastal marine environment using the MAREL buoy. Journal of environmental monitoring, 6, 569-575.

Cassou, C., Terray, L., Hurrell, J. W., Deser, C., 2004. North Atlantic winter climate regimes: Spatial asymmetry, stationarity with time, and oceanic forcing. Journal of Climate, 17(5), $1055-1068$.

Chapelle, A., Lazure, P., Ménesguen, A., 1994. Modeling eutrophication events in a coastal ecosystem; sensitivity analysis. Est. Coast. Mar. Sci. 39, 529-548.

Cugier P., Le Hir P., 2002. Development of a 3D hydrodynamic model for coastal ecosystem modelling. Application to the plume of the Seine River (France). Estuarine, Coastal and Shelf Science, 55(5), 673-695.

Desmit X, Thieu V, Billen G, Campuzano F, Dulière V, Garnier J, Lassaletta L, Ménesguen A., Neves R, Pinto L., Silvestre M, Sobrinho JL, Lacroix G., 2018. Reducing marine eutrophication may require a paradigmatic change. Science of the total environment, 635, 1444-1466. 
Directive 2000/60/EC of the European Parliament and of the Council of 23 October 2000

establishing a framework for Community action in the field of water policy (Water Framework Directive). Off. J. Eur. Communities L 327/1 (December 22).

Directive 2008/56/EC of the European Parliament and of the Council of 17 June 2008 establishing a framework for community action in the field of marine environmental policy (Marine Strategy Framework Directive). Off. J. Eur. Union L 164/19 (June 25).

Doney S.C., Lima I., Moore J.K., Lindsay K., Behrenfeld M.J., Westberry T.K., Mahowald N., Glover D. M., Takahashi T., 2009. Skill metrics for confronting global upper ocean ecosystem-biogeochemistry models against field and remote sensing data. Journal of Marine Systems, 76(1-2), 95 - 112.

Edwards K. P., Barciela R., Butenschön M., 2012. Validation of the NEMO-ERSEM operational ecosystem model for the North West European Continental Shelf. Ocean Sci. Discuss., 9, 745-786.

Eilola K., Meier H.E.M., Almroth E., 2009. On the dynamics of oxygen, phosphorus and cyanobacteria in the Baltic sea: a model study. J. Mar. Syst., 75, 163-184.

Ford D. A., van der Molen J., Hyder K., Bacon J., Barciela R., Creach V., McEwan R., Ruardij P., Forster R., 2017. Obserying and modelling phytoplankton community structure in the North Sea. Biogeosciences, 14, 1419-1444.

Gohin, F., 2011, Annual cycles of chlorophyll-a, non-algal suspended particulate matter, and turbidity observed from space and in-situ in coastal waters. Ocean Sci. 7: 705-732.

Gohin, F., Druon, J.N. and Lampert, L., 2002. A five channel chlorophyll concentration algorithm applied to SeaWiFS data processed by SeaDAS in coastal waters. International Journal of Remote Sensing, 8(23): 1639-1661.

Gohin, F., Loyer, S., Lunven, M., Labry, C., Froidefond, J.-M., Delmas, D., Huret, M. and Herbland, A., 2005. Satellite-derived parameters for biological modelling in coastal waters: Illustration over the eastern continental shelf of the Bay of Biscay. Remote Sensing of Environment, 95: 29-46. 
Guillaud, J.-F., Bouriel L., 2007. Relationships between nitrate concentration and river flow, and temporal trends of nitrate in 25 rivers of Brittany (France). Revue des Sciences de l'Eau, $20(2): 213-226$.

Guillaud J.F., Ménesguen A., 1998. Modélisation sur vingt ans (1976-1995) de la production phytoplanctonique en Baie de Seine (France), Oceanol. Acta, 21(6): 887-906.

Hill, A. E., Brown, J., Fernand, L., Holt, J., Horsburgh, K. J., Proctor, R., Raine, R., Turrell, W. R., 2008. Thermohaline circulation of shallow tidal seas. Geophysical Research Letters, 35(11).

Huret, M., F. Gohin, D. Demas, M. Lunven, V. Garçon, 2007. Use of SeaWiFS data for light availability and parameter estimation of a phytoplankton production model of the Bay of Biscay. Journal of Marine Systems, 65(1-4): 509-531.

Huret M., Sourisseau M., Petitgas P., Struski C., Léger F., Lazure P., 2013. A multi-decadal hindcast of a physical-biogeochemical model and derived oceanographic indices in the Bay of Biscay. Journal of Marine Systems, 109, S77-S94.

Kersalé M., Marie L., Le Cann B., Serpette A., Lathuiliere C., Le Boyer A., Lazure, P., 2016. Poleward along-shore current pulses on the inner shelf of the Bay of Biscay. Estuarine, Coastal and Shelf Science, 179, 155-171.

Koutsikopoulos C., Le Cann B., 1996. Physical processes and hydrological structures related to the Bay of Biscay anchovy. Scientia Marina, 60, 9-19.

Lacroix G., Desmit X., Dulière V., Lancelot C., Gypens N., Ménesguen A., Thouvenin B., Dussauze M., Billen G., Garnier J., Thieu V., Silvestre M., Passy P., Lassaletta L., Guittard G., Théry S., Neves R., Campuzano F., Garcia C., Pinto L., Sobrinho J., Mateus M., Ascione Kenov I., 2015. Ecosystem Models as Support to Eutrophication Management in the North Atlantic Ocean, final report of the ERANET SEAS-ERA EMoSEM project, 174 p.

Lacroix G., Ruddick K., Park Y., Gypens N., Lancelot C., 2007. Validation of the 3D biogeochemical model MIRO\&CO with field nutrient and phytoplankton data and MERISderived surface chlorophyll a images. Journal of Marine Systems, 64(1-4), 66-88. 
Lampert L., Queguiner B., Labasque T., Pichon A., Lebreton N., 2002. Spatial variability of phytoplankton composition and biomass on the eastern continental shelf of the Bay of Biscay (north-east Atlantic Ocean): evidence for a bloom of Emiliania huxleyi (Prymnesiophyceae) in spring 1998. Cont. Shelf Res., 22, 1225-1247.

Lancelot, C., Billen, G., Sournia, A., Weisse, T., Colijn, F., Veldhuis, M., Davies, A., Wassmann, P., 1987. Phaeocystis blooms and nutrient enrichment in the continental coastal zones of the North Sea. Ambio, 16, 38-46.

Lancelot C., Gypens N., Billen G., Garnier J., Roubeix, V., 2007. Testing an integrated riverocean mathematical tool for linking marine eutrophication to land use: the Phaeocystis dominated Belgian coastal zone (Southern North Sea) over the past 50 years. J. Mar. Syst., 64: $216-228$.

Lazure, P, Jegou, A. M., 1998. 3D modelling of seasonal evolution of Loire and Gironde plumes on Biscay Bay continental shelf. Oceanologica acta, 21(2), 165-177.

Lazure P., Le Boyer A., Marié L., 2014. The unexpected nature of the tidal currents observed off the Landes coast $\left(44^{\circ} \mathrm{N}\right)$. Isobay 14 - XIVth International Symposium on Oceanography of the Bay of Biscay. 11-13 June, 2014, Bordeaux. (http://archimer.ifremer.fr/doc/00315/42571) Lazure P., Dumas F., 2008. An external-internal mode coupling for a 3D hydrodynamical model for applications at regional scale (MARS). Advances in Water Resources, 31(2), 233250.

Le Boyer A., Cambon G., Daniault N., Herbette S., Le Cann B., Marié L., Morin, P., 2009. Observations of the Ushant tidal front in September 2007. Continental Shelf Research, 29(8), $1026-1037$.

Le Boyer A., Charria G., Le Cann B., Lazure P., Marié L., 2013. Circulation on the shelf and the upper slope of the Bay of Biscay. Continental Shelf Research, 55, 97-107.

Le Cann, B., 1990. Barotropic tidal dynamics of the Bay of Biscay shelf: observations, numerical modelling and physical interpretation. Continental Shelf Research, 10(8), 723-758. 
Lenhart, H.-J., Mills, D.K., Baretta-Bekker, H., van Leeuwen, S.M., der Molen, J.v., Baretta, J.W., Blaas, M., Desmit, X., Kühn, W., Lacroix, G., Los, H.J., Ménesguen, A., Neves, R., Proctor, R., Ruardij, P., Skogen, M.D., Vanhoutte-Brunier, A., Villars, M.T., Wakelin, S.L., 2010. Predicting the consequences of nutrient reduction on the eutrophication status of the North Sea. J. Mar. Syst. 81 (1-2), 148-170.

Loyer, S., 2001. Modélisation de la production phytoplanctonique dans la zone côtière atlantique enrichie par les apports fluviaux. Ph. D. thesis, Université de Paris VI, 232 pp.

Loyer S., Lampert L., Ménesguen A., Cann P., Labasque T., 2006. Seasonal evolution of the nutrient pattern on Biscay Bay continental shelf over the years 1999-2000. Scientia marina, $70(1), 31-46$.

Ménesguen, A., P. Cugier, I. Leblond, 2006. A new numerical technique for tracking chemical species in a multi-source, coastal ecosystem, applied to nitrogen causing Ulva blooms in the Bay of Brest (France). Limnology and. Oceanography, 51, 591-601.

(http://aslo.org/lo/toc/vol_51/issue_1_part_2/0591.pdf)

Ménesguen A., Cugier P., Loyer S., Vanhoutte-Brunier A., Hoch T., Guillaud J.-F., Gohin F., 2007. Two- or three-layered box-models versus fine 3D-models for coastal ecological modelling? A comparative study in the English Channel (Western Europe). J.Mar. Sys., 64, 47-65.

Ménesguen A., Desmit X., Dulière V., Lacroix G., Thouvenin B., Thieu V., Dussauze M., 2018a. How to avoid eutrophication in coastal seas? A new approach to derive river-specific combined nitrate and phosphate maximum concentrations. Science of the total environment, 628-629, $400-414$

Ménesguen A., Dussauze M., Dumas F., 2018b. Designing optimal scenarios of nutrient loading reduction in a WFD/MSFD perspective by using passive tracers in a biogeochemical3D model of the English Channel/Bay of Biscay area. Ocean and Coastal Management. 163C, 37-53. 
Napoléon, C., Fiant, L., Raimbault, V., Claquin, P., 2013. Study of dynamics of phytoplankton and photosynthetic parameters using opportunity ships in the western English Channel. Journal of Marine Systems, 128, 146-158.

Napoléon, C., Raimbault, V., Fiant, L., Riou, P., Lefebvre, S., Lampert, L., Claquin, P., 2012. Spatiotemporal dynamics of physicochemical and photosynthetic parameters in the central English Channel. J. Sea Res. 69, 43-52.

OSPAR Commission, 2003. OSPAR Integrated Report 2003 on the Eutrophication Status of the OSPAR Maritime Area Based Upon the First Application of the Comprehensive Procedure. https://www.ospar.org/documents?v=6962

Planque B., Lazure P., Jégou A. M.,,2004. Detecting hydrological landscapes over the Bay of Biscay continental shelf in spring. Climate research, 28(1), 41-52.

Piroddi, C., Teixeira, H., Lynam, C. P., Smith, C., Alvarez, M. C., Mazik, K., Andonegi, E., Churilova, T., Tedesco, L., Chifflet, M., Chust, G., 2015. Using ecological models to assess ecosystem status in support of the European Marine Strategy Framework Directive, Ecol. Indic., 58, 175-191.

Puillat I., Lazure P., Jegou A. M., Lampert L., Miller P. I., 2004. Hydrographical variability on the French continental shelf in the Bay of Biscay, during the 1990s. Continental shelf research, 24(10), 1143-1163.

Rascle, N., Ardhuin, F., 2013. A global wave parameter database for geophysical applications. Part 2: Model validation with improved source term parameterization. Ocean Modelling, 70, 174-188.

Reguera B., Riobó P., Rodríguez F., Díaz P. A., Pizarro G., Paz B., Franco J.M., Blanco J., 2014. Dinophysis toxins: causative organisms, distribution and fate in shellfish. Marine Drugs, 12(1), 394-461.

Salomon J. C., Breton M., 1993. An atlas of long-term currents in the Channel. Oceanologica Acta, 16(5-6), 439-448. 
Savchuk O.P., Gustafsson Bo G., Müller-Karulis B., 2012. BALTSEM - A marine model for decision support within the Baltic Sea region. Baltic Nest Institute Technical Report Series, No. 7, 55 p.

Schrum C., Alekseeva I., St John M., 2006. Development of a coupled physical-biological ecosystem model ECOSMO. J. Mar. Syst., 61, 79-99.

Siddorn J.R., Allen J.I., Blackford J.C., Gilbert F.J., Holt J.T., Holt M.W., Osborne J.P., Proctor R., Mills D.K., 2007. Modelling the hydrodynamics and ecosystem of the North-West European continental shelf for operational oceanography. Journal of Marine Systems, 65, 417-429.

Skogen, M.D., Eilola, K., Hansen, J.L.S., Meier, H.E.M., Molchanov, M.S., Ryabchenko, V.A., 2014. Eutrophication status of the North Sea, Skagerrak, Kattegat and the Baltic Sea in present and future climates: a model study. J. Mar. Syst., 132 (0), 174-184.

Skogen, M.D., Mathisen, L.R., 2009. Long-term effects of reduced nutrient inputs to the North Sea. Estuar. Coast. Shelf Sci., 82 (3), 433-442.

Smith, E.L., 1936. Photosynthesis in relation to light and carbon dioxide. Proceedings of the National Academy of Sciences, 22: 504-511.

Smyth, T. J., Fishwick, J. R., AL-Moosawi, L., Cummings, D. G., Harris, C., Kitidis, V., Rees, A., Martinez-Vicente, V., Woodward, E. M. S., 2010. A broad spatio-temporal view of the Western English Channel observatory, J. Plankton Res., 32, 585-601.

Smythe-Wright D., Daniel A., Boswell S., Purcell D., Hartman M., Hartman S., Hydes D., 2014. Phytoplankton and pigment studies in the Bay of Biscay and English Channel. DeepSea Research Part II: Topical Studies in Oceanography, 106, 76-86.

Sohma, A., Sekiguchi, Y., Kuwae, T., Nakamura, Y., 2008. A benthic-pelagic coupled ecosystem model to estimate the hypoxic estuary including tidal flat - Model description and validation of seasonal/daily dynamics. Ecological Modelling 215, 10-39. 
Sourisseau M., Jégou K., Lunven M., Quéré J., Gohin F., Bryère P., 2016. Distribution and dynamics of two species of Dinophyceae producing high biomass blooms over the French Atlantic shelf. Harmful Algae, 53, 53-63.

Sournia, A., Belin, C., Catherine, M., Erard-Le Denn, E., Fresnel, J., Pastoureaud, A., Soulard, R., 1992. The repetitive and expanding occurrence of a green, bloom-forming dinoflagellate (Dinophyceae) on the coasts of France. Cryptogamie, Algol. 13, 1-13.

Tilstone G., Mallor-Hoya S., Gohin F., Couto A. B., Sa C., Goela P., Cristina S., Airs R., Icely J., Zuehlke M., Groom S., 2017. Which ocean colour algorithm for MERIS in North West European waters? Remote Sensing Of Environment, 189, 132-151.

Van der Molen J., Ruardij P., Greenwood N., 2017. A 3D SPM model for biogeochemical modelling, with application to the northwest European continental shelf, J. Sea Res., 127, 6381.

van Leeuwen, S., Tett P., Mills D., van der Molen J., 2015. Stratified and nonstratified areas in the North Sea: Long-term variability and biological and policy implications, J. Geophys. Res. Oceans, 120, 4670-4686

Wakelin S.L., Artioli Y., Butenschön M, Allen, J.I., Holt J.T., 2015. Modelling the combined impacts of climate change and direct anthropogenic drivers on the ecosystem of the northwest European continental shelf. Journal of Marine Systems, 152, 51-63.

Wan Z., She J., Maar M., Jonasson L., Baasch-Larsen J., 2012. Assessment of a physicalbiogeochemical coupled model system for operational service in the Baltic Sea. Ocean Sci. Discuss., 9, 835-876.

Yankoysky A. E., 2006. On the validity of thermal wind balance in alongshelf currents off the New Jersey coast. Continental shelf research, 26(10), 1171-1183. 


\section{Figure captions}

Figure 1. Bathymetric grid of the domain, with the location of the coastal monitoring stations (stars) and ferrybox transects (yellow lines and names) used for validation. The white contours delineate the 3 MSFD sub-regions under French jurisdiction.

Figure 2. Flow diagram of the biogeochemical model. In blue: inorganic and detrital forms of nitrogen, in mauve: inorganic and detrital forms of phosphorus, in green: diatoms and dissolved silicate and detrital forms of silicon, in yellow: nanoflagellates, in orange: dinoflagellates, in red: zooplanktonic groups.

Figure 3. Map of sea surface temperature averaged over the 2000-2010 decade (left: model result, right: AVHRR remote sensed data)

Figure 4. Map of sea surface chlorophyll $90^{\text {th }}$ percentile computed oyer the productive period (March-October) along the 2000-2010 decade (left: mødel result, right: MODIS satellite data). The limits between the bathymetric strata are superimposed to the satellite map.

Figure 5. Scatter-plot of simulated simulated (y-axis) versus measured (x-axis) values for mean SST (upper panel) and chlorophyll $90^{\text {th }}$ percentile (lower panel) over the whole domain during 2000-2010 decade. Solid lines are the linear regressions adjusted to the data set, the dotted line is the line with slope 1 and intercept 0 .

Figure 6. Time-series of satellite measurements (in grey) and simulated (in black) daily values of SST averaged on 4 different bathymetric strata: 0-25m (A), 25-40m (B), 40-200m (C), 200-6000m (D). Y axis scale is the same for the 4 graphs.

Figure 7. Time-series of satellite measurements (in grey) and simulated (in black) daily values of surface chlorophyll, averaged on 4 different bathymetric strata: 0-25m (A), 25-40m (B), 40-200m (C), 200-6000m (D). Y axis scale is specific of each graph.

Figure 8. Hovmöller diagrams for temperature, salinity, chlorophyll, nitrate, phosphate and silicate in surface waters along the Southampton-Bilbao track of the MV_Pride_of_Bilbao during 2010 (left panels: ferrybox measurements from Smythe-Wright et al., 2014; right panels: this ECO-MARS3D model). 
Figure 9. Hovmöller diagrams for temperature, salinity, chlorophyll, nitrate, phosphate and silicate in surface waters along the Ouistreham-Portsmouth track of the $M V \_$Normandie during 2010 (left panels: ferrybox measurements from Napoléon et al., 2012; right panels: this ECO-MARS3D model).

Figure 10. Surface temperature time-series at 6 coastal monitoring stations. Field measurements are represented by black dots, simulation by a grey solid line.

Figure 11. Comparison of field measurements (symbols) and simulation (solid line) of temperature at the E1 station, south of Plymouth. Upper panel: time-series of surface (grey) and bottom (black) temperatures; lower panel: summer vertical profiles at four different years. Figure 12. Surface nitrate time-series at 6 coastal monitoring stations.) Field measurements are represented by black dots, simulation by a grey solid line.

Figure 13. Surface chlorophyll time-series at 6 coastal monitoring stations. Field measurements are represented by black dots, satellite-derived chlorophyll by a green solid line and simulation by a grey solid line.

Figure 14. Dissolved oxygen time series at the MOLIT buoy location in Vilaine bay in surface and bottom layers; measurements: dots, simulation: bold solid lines, saturation concentration: black dots.

Figure 15. Taylor's diagrams for temperature, salinity, nitrate, silicate, phosphate and chlorophyll at 6 stations (surface layer), and for dissolved oxygen at the MOLIT buoy location in Vilaine bay (surface and bottom layers). For chlorophyll, the results for the four bathymetric strata and for the global map of $90^{\text {th }}$ percentile have been added for comparison with stations.

Figure 16. Decadal (2000-2010) distribution of meshes which are not in Good Environmental Status. For winter nutrient concentrations: January-February mean of (a) nitrate, phosphate); for spring-summer descriptors of eutrophication effects: March-October $90^{\text {th }}$ percentile of simulated (c) and observed (d) surface chlorophyll. 




Figure 1 


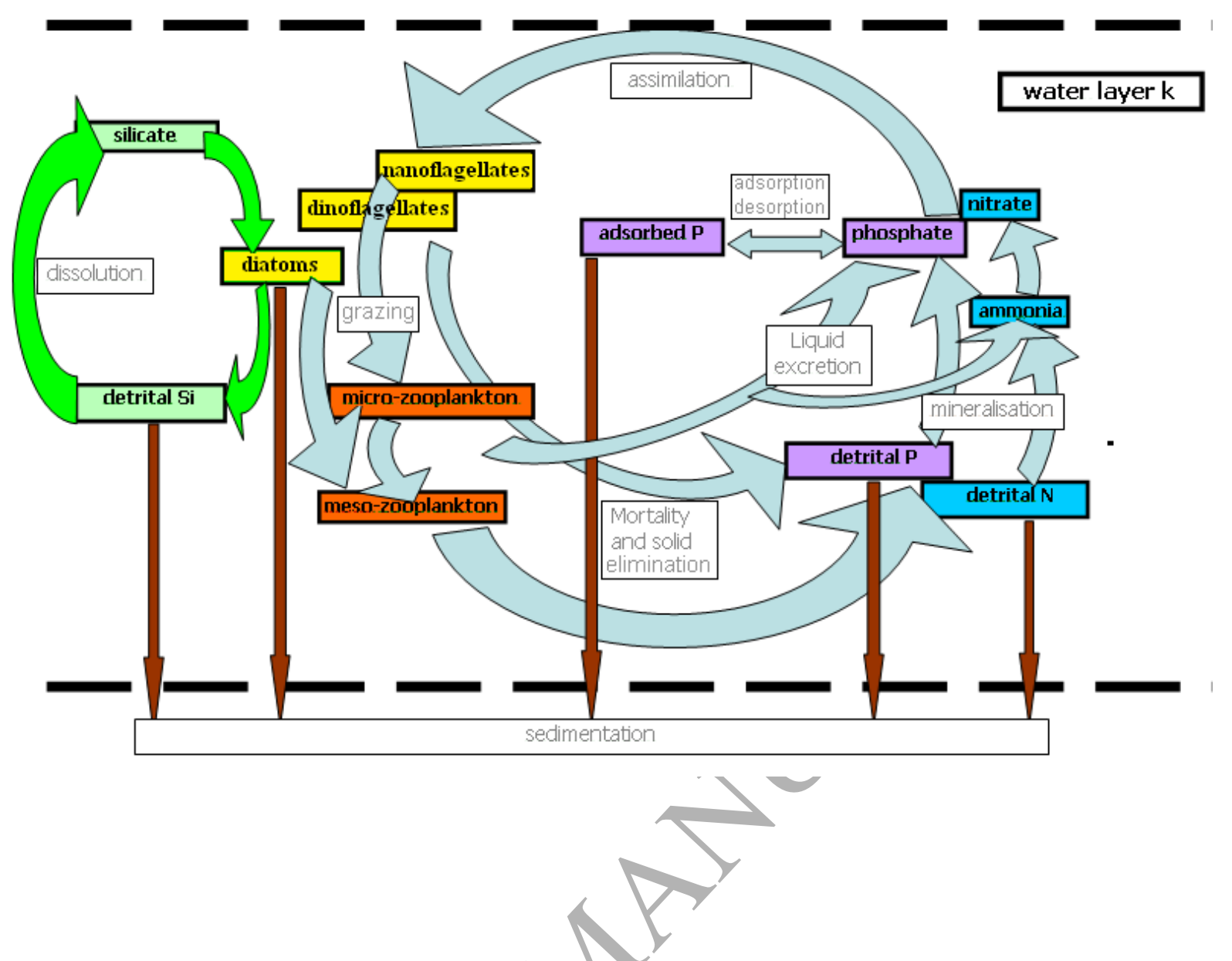

Figure 2 


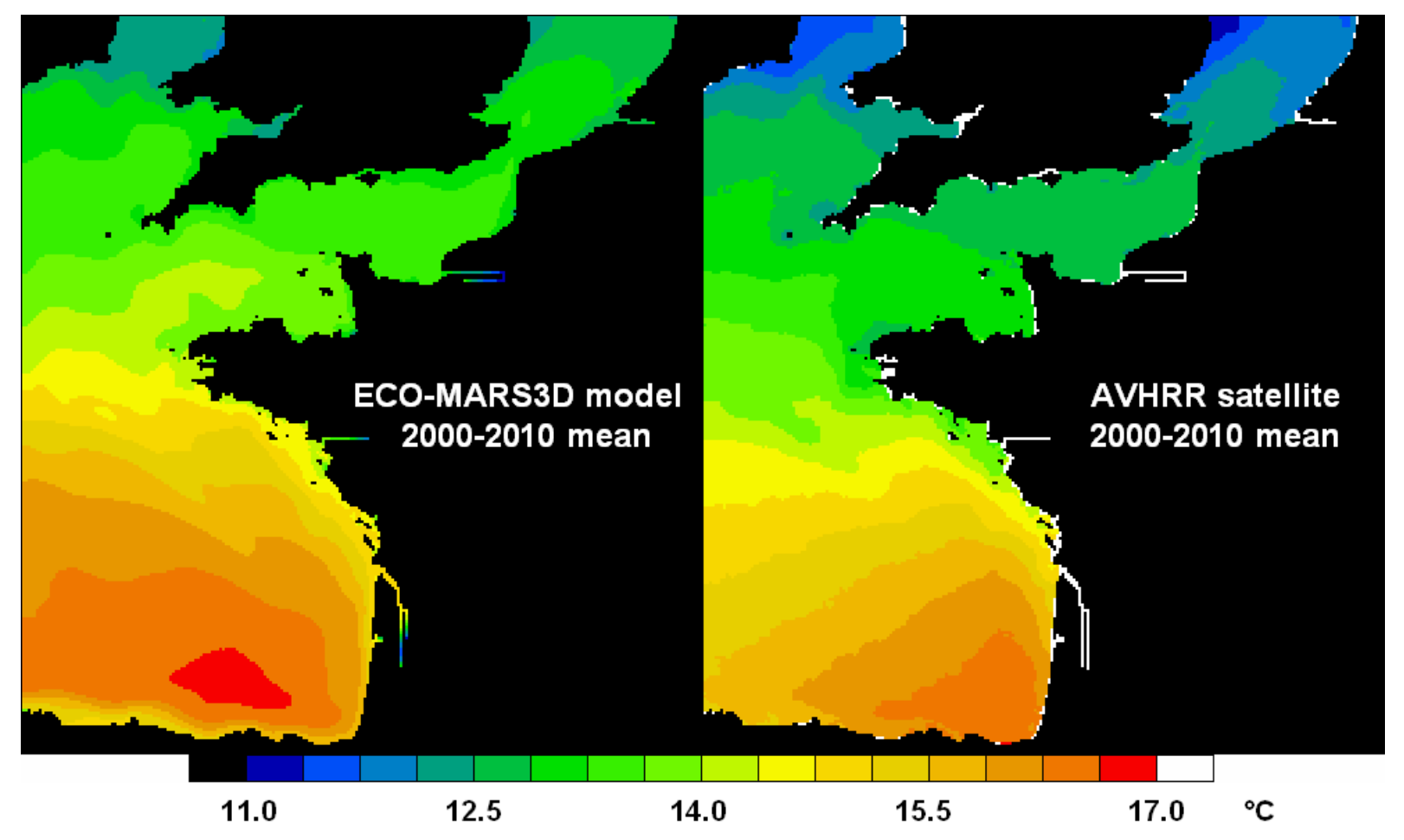

Figure 3 


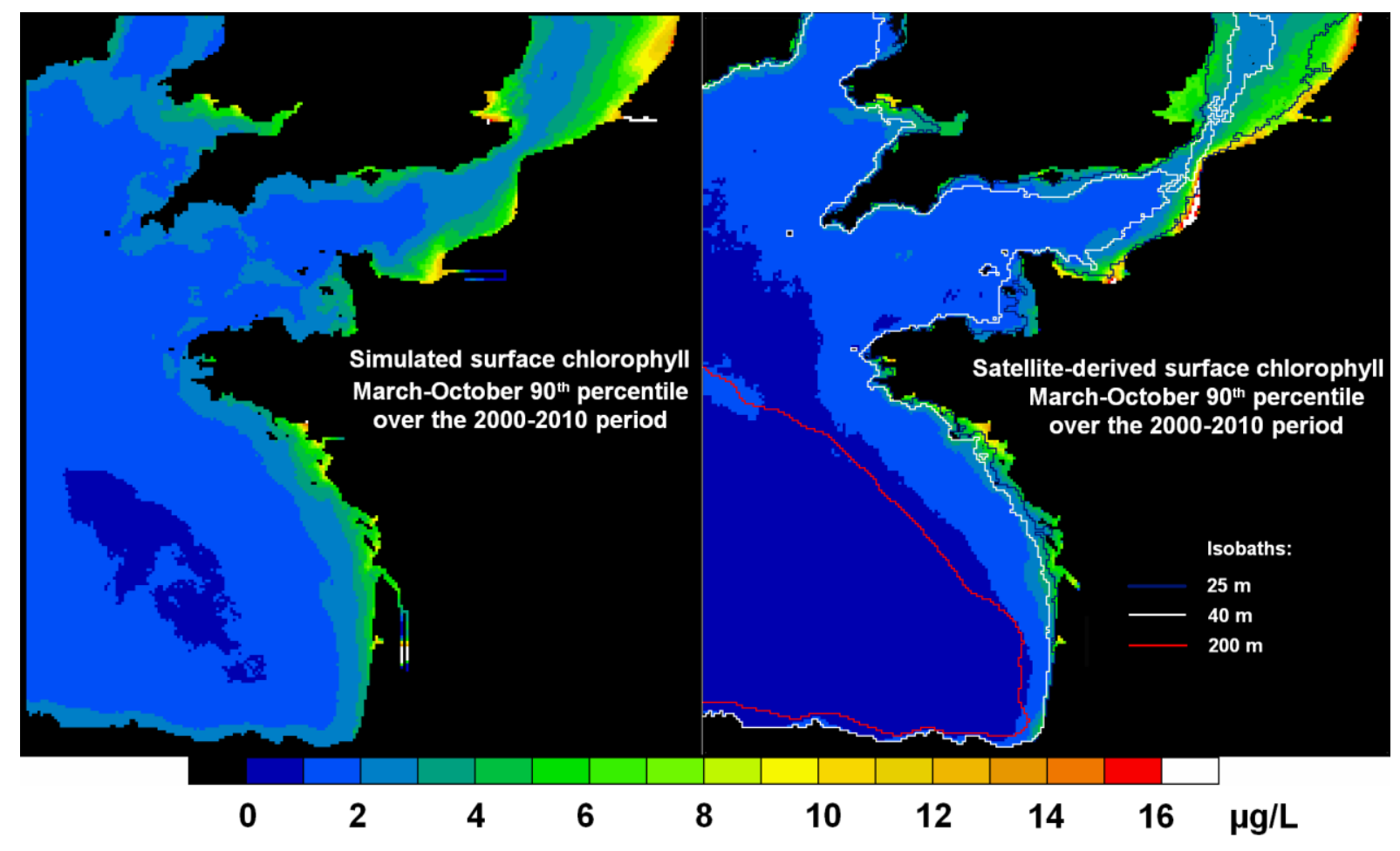

Figure 4 

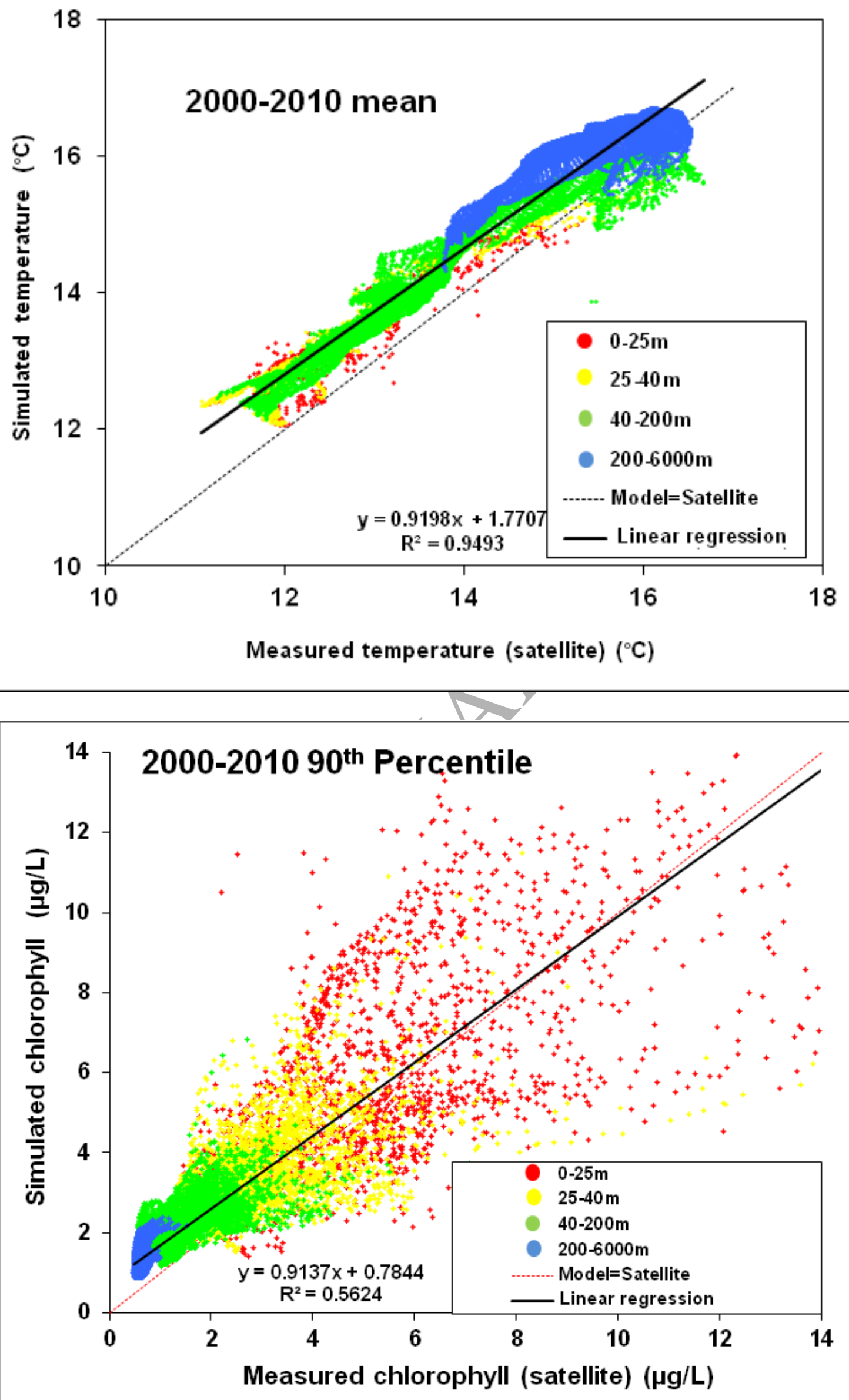

Figure 5 

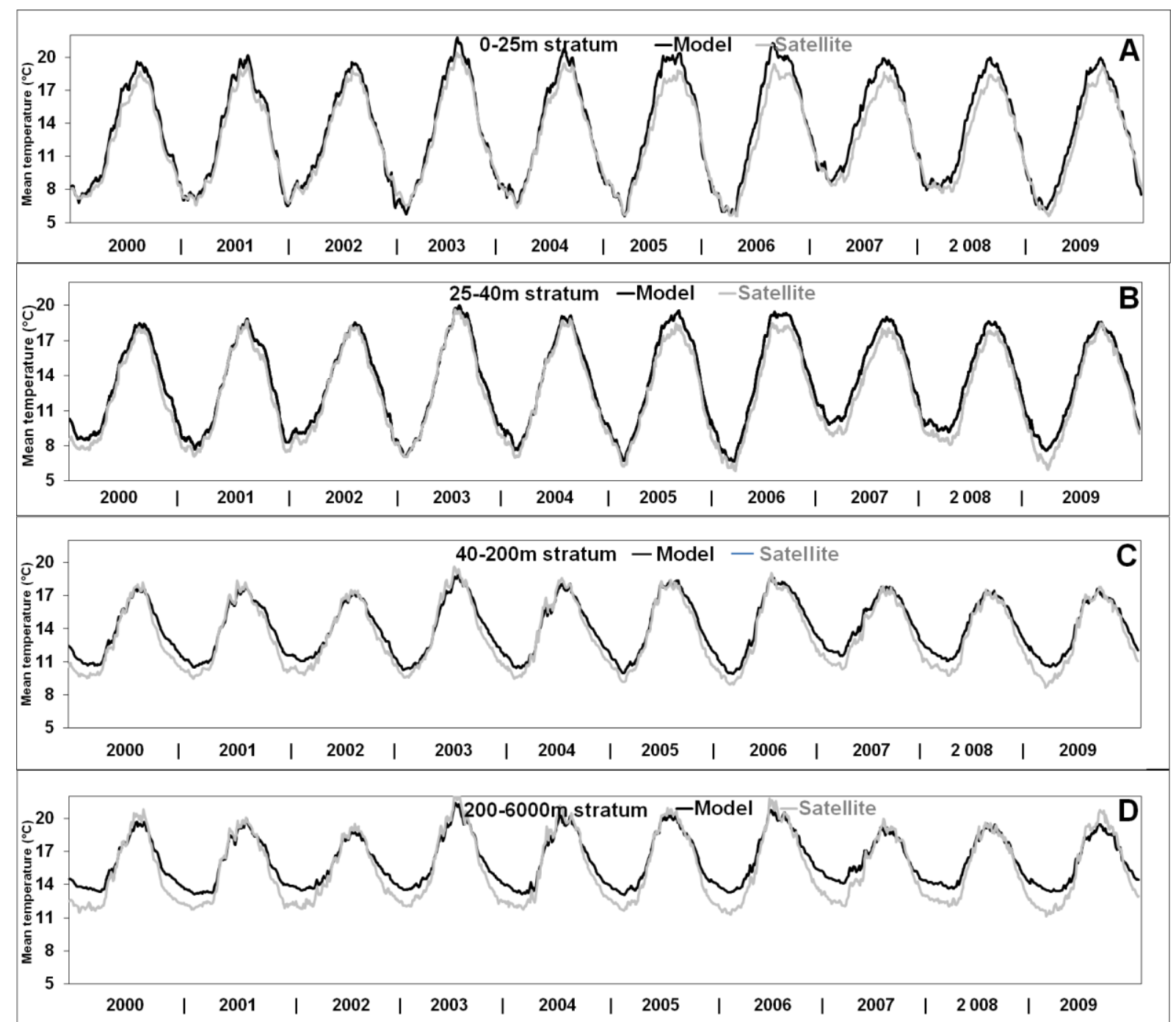

Figure 6 


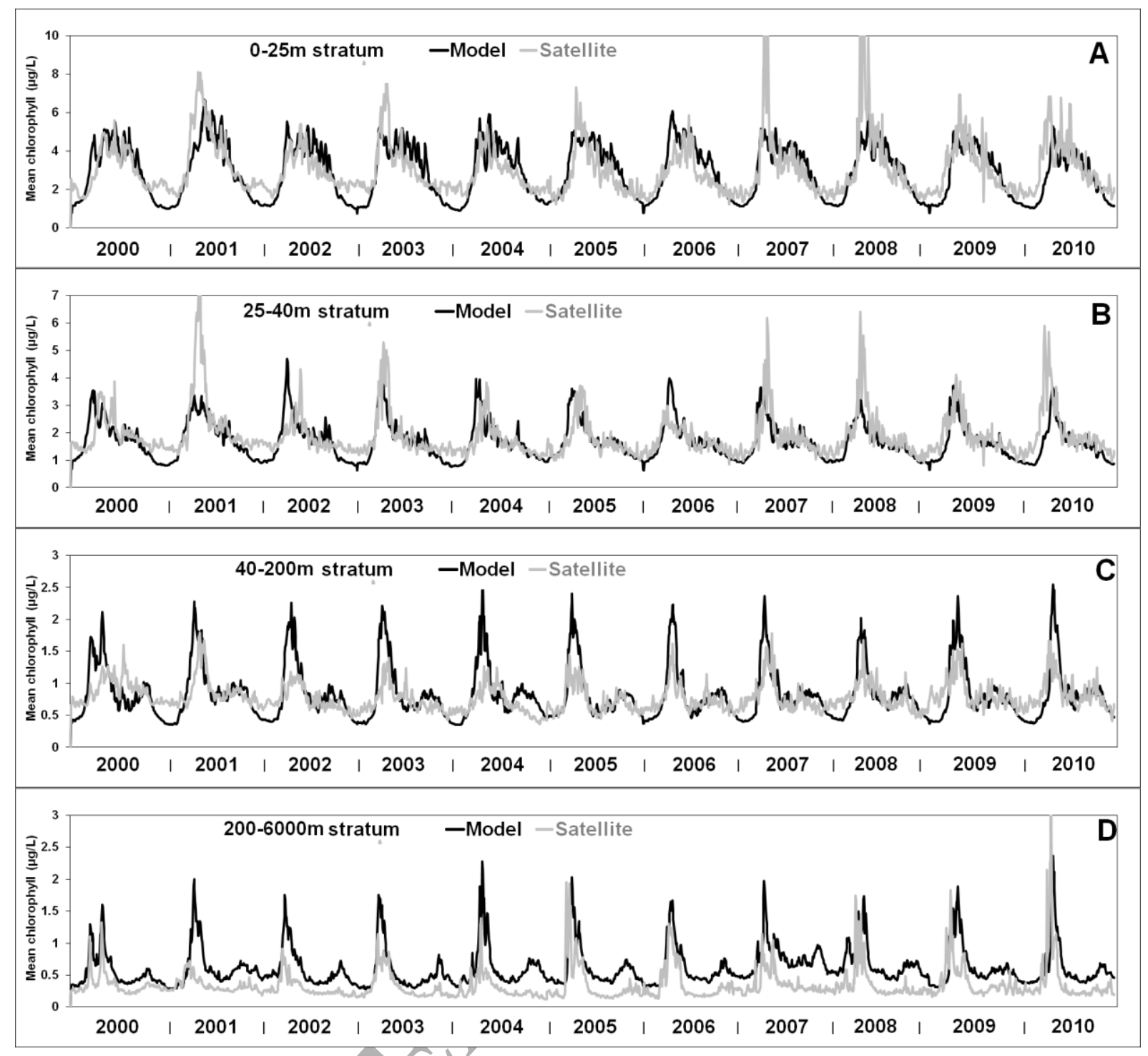

Figure 7 

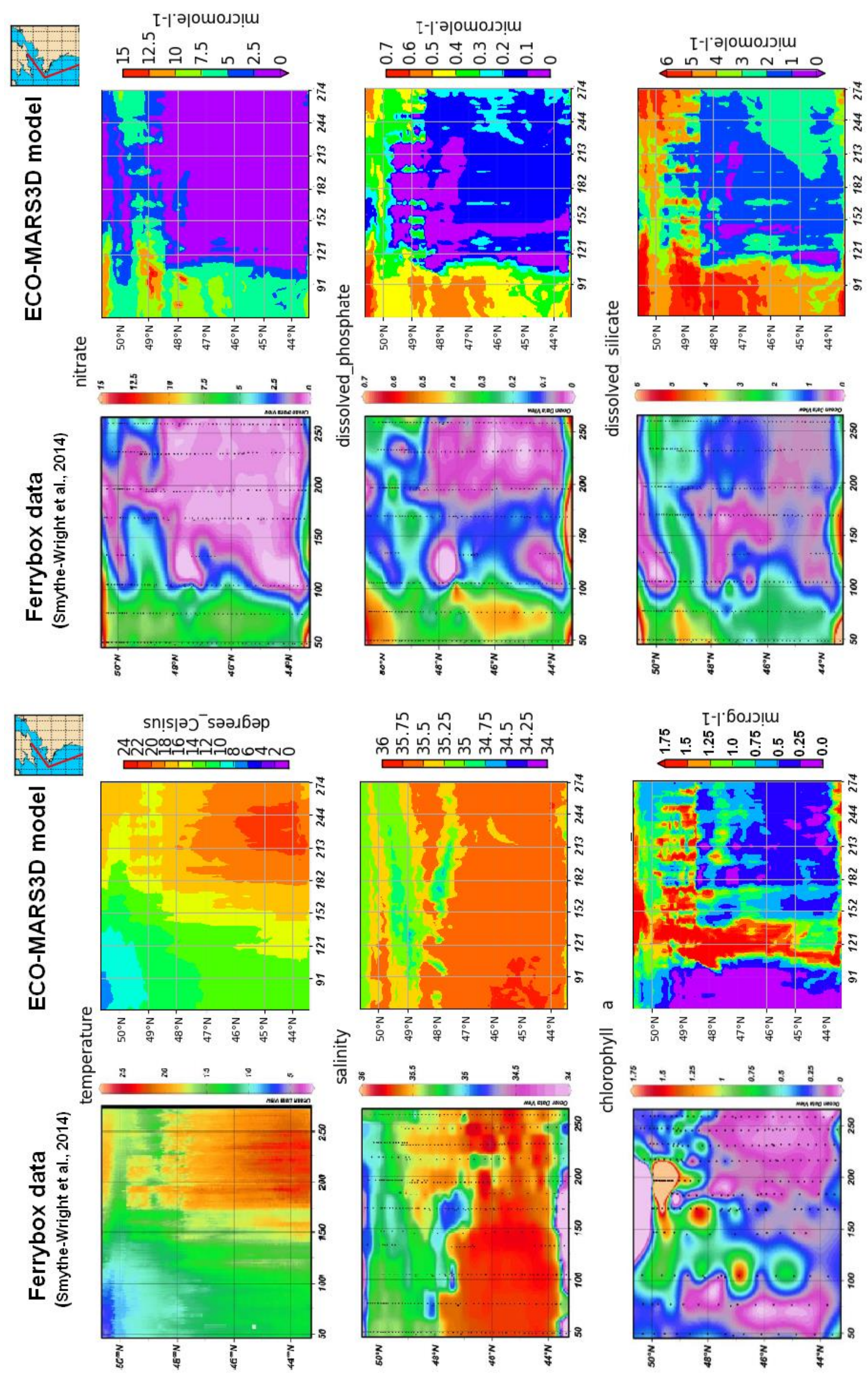

Figure 8 


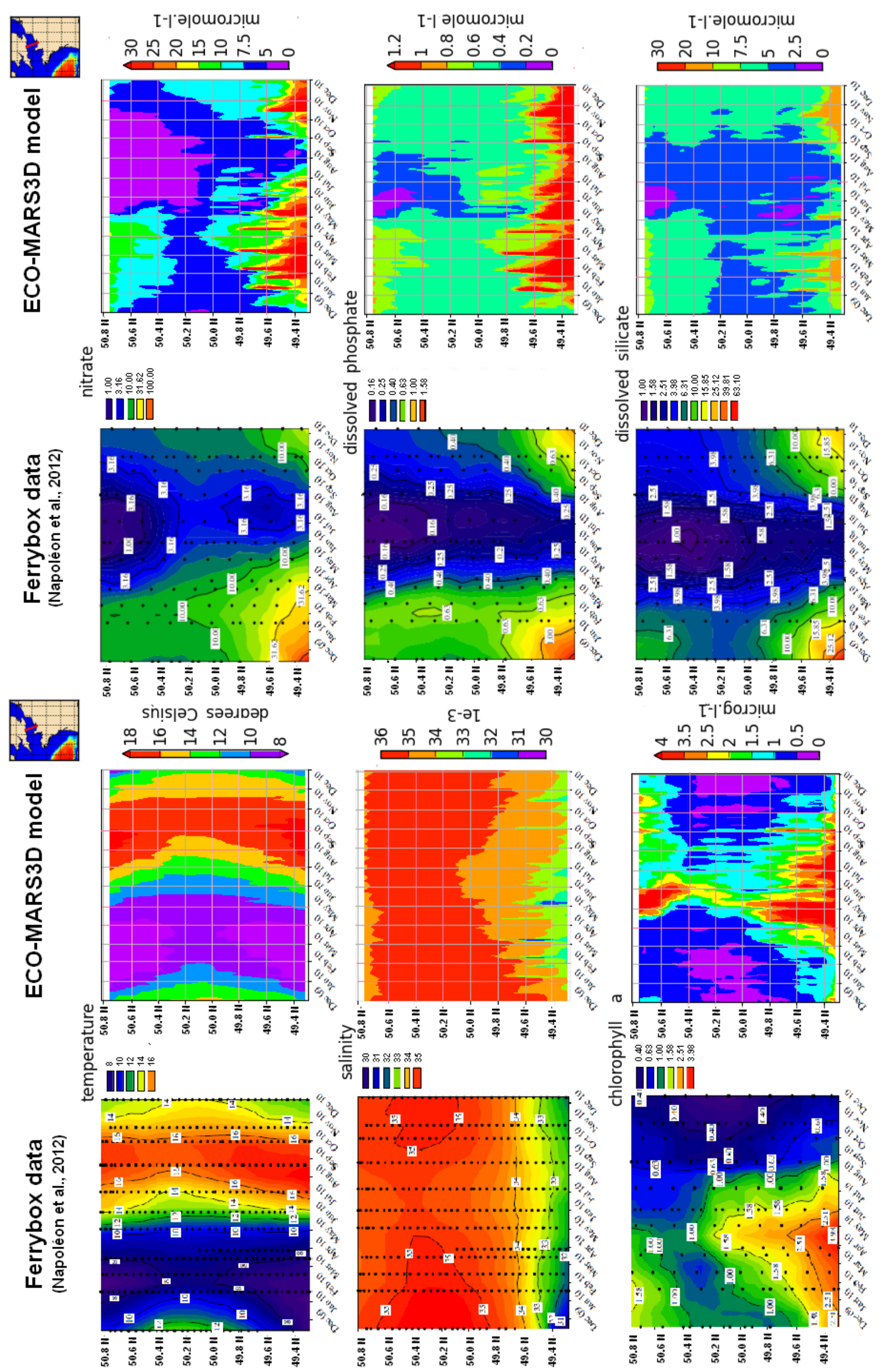

Figure 9 



Figure 10 


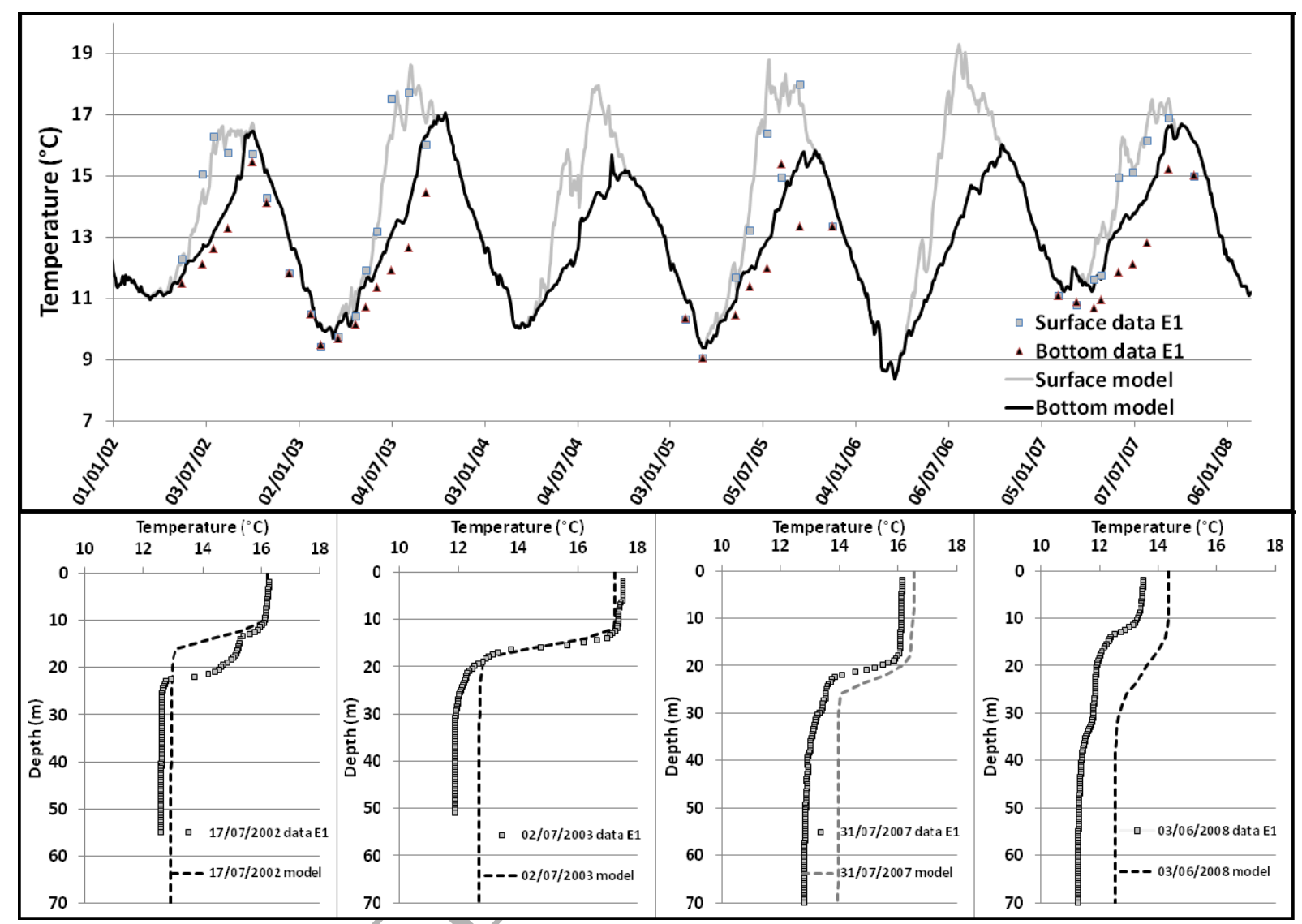

Figure 11 


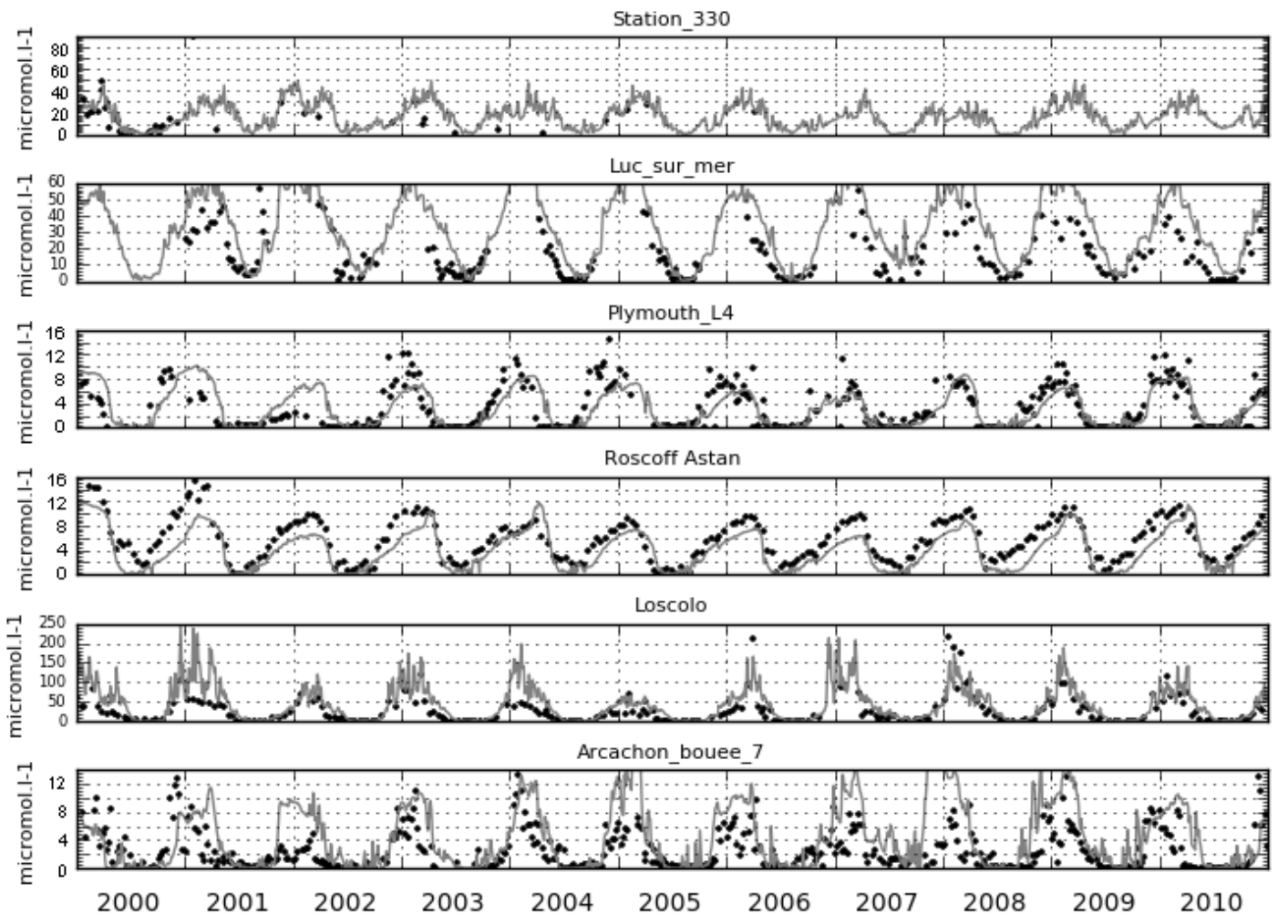

Figure 12 

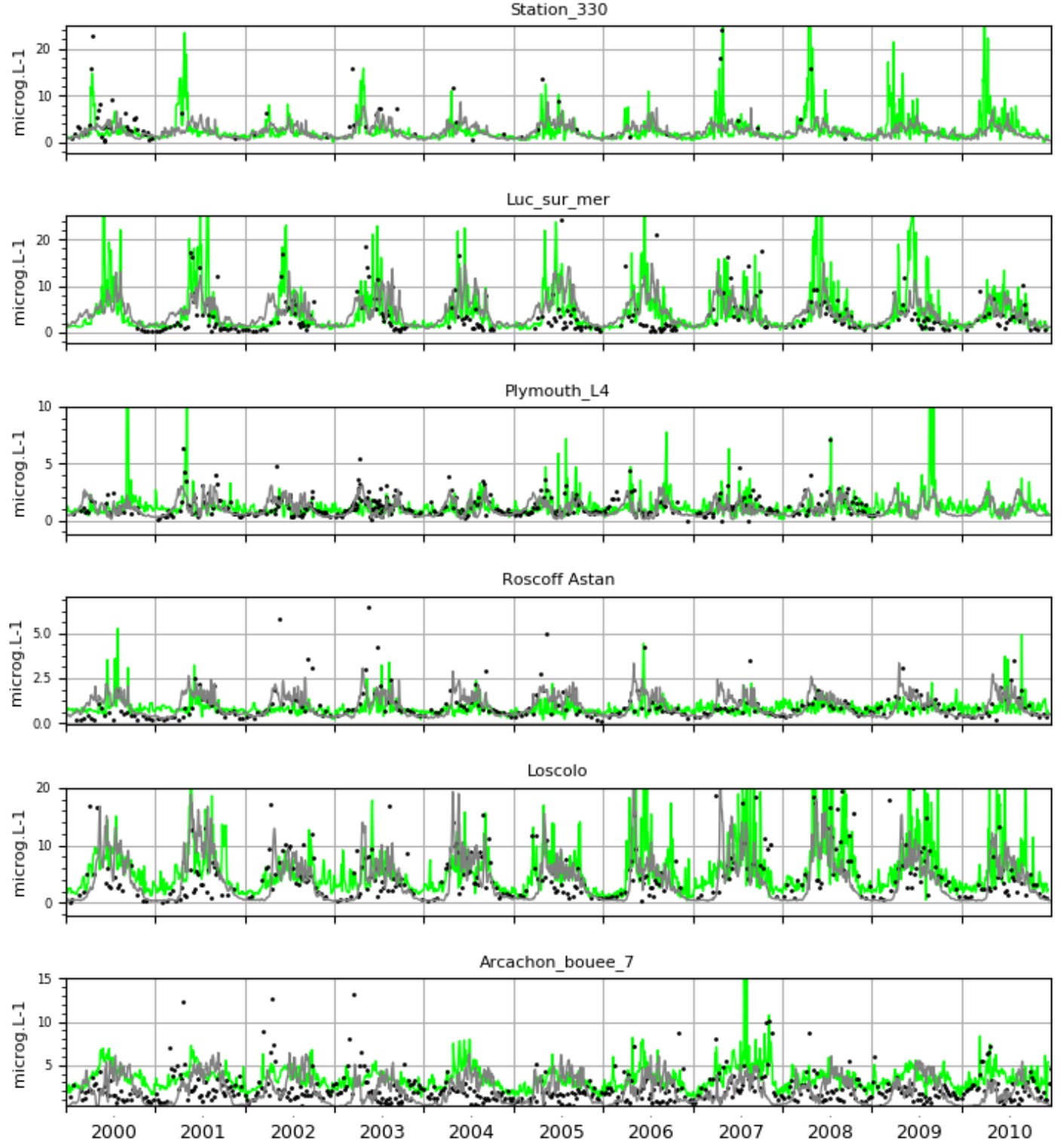

Figure 13 




Figure 14 



- Station 330

$\star$ Luc/mer

Astan

$\Delta$ Plymouth L4

- Loscolo

4 Arcachon
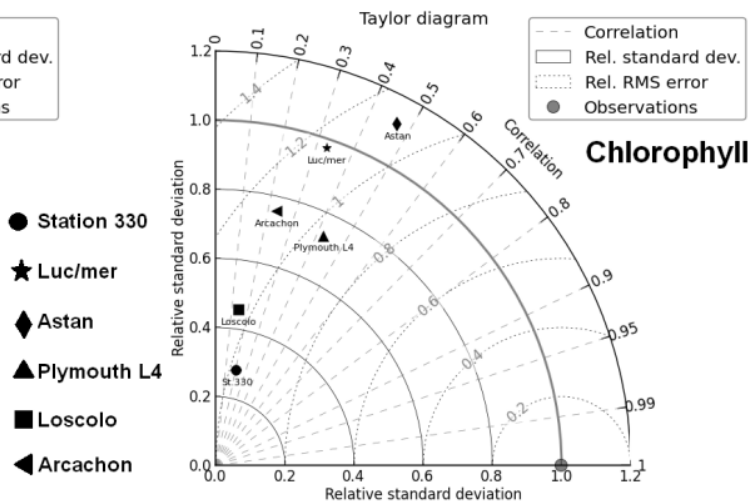

Oxygen

Taylor diagram

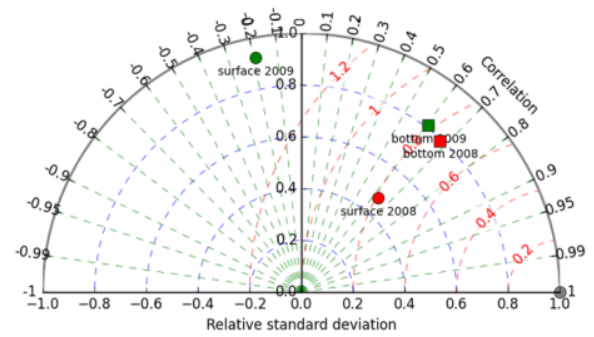

Figure 15 

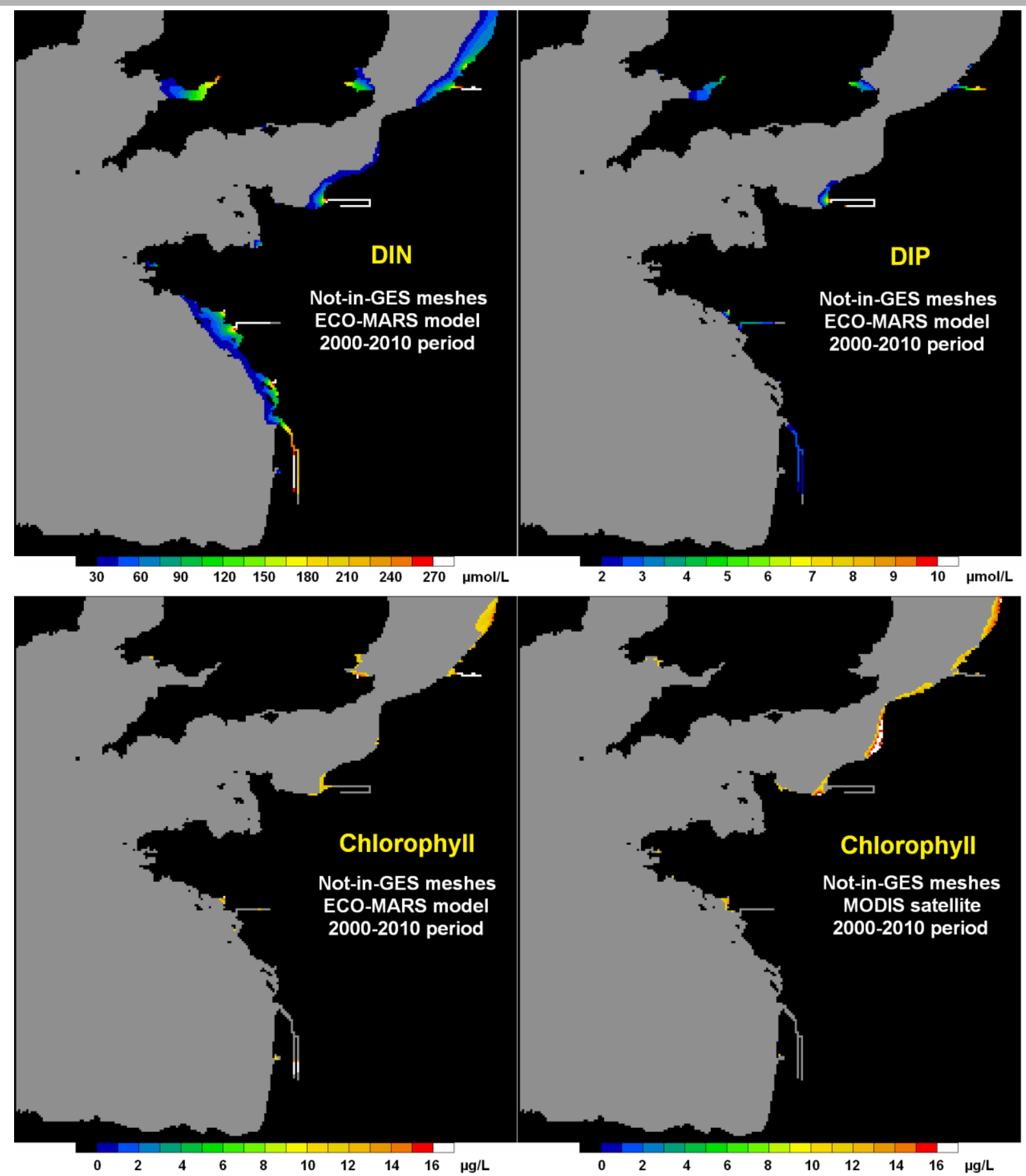

Figure 16 


\section{Appendix A.}

Equations of the biogeochemical processes occurring in the water layer located between depths $\mathrm{z}_{\min }$ and $\mathrm{z}_{\max }$.

In the absence of sediment layer, benthic state variables are attached in the bottom water layer and are expressed per surface unit.

$\mathrm{X}_{\mathrm{SM}}$ is a conservative state variable simulating the fate of inorganic suspended matter brought by the rivers.

Ammonium $\mathrm{X}_{1}\left(\mu \mathrm{mol} \mathrm{L} \mathrm{L}^{-1}\right)$ :

(Equation 1)

$\frac{\mathrm{dX}_{1}}{\mathrm{dt}}=\mathrm{k}_{\min \mathrm{N}} \mathrm{f}_{\mathrm{T}} \mathrm{X}_{11}-\mu_{\text {max diat }} \mathrm{rNH} 4_{\text {diat }} \mathrm{f}_{\mathrm{T}} \min \left(\mathrm{f}_{\text {Ndiat }}, \mathrm{f}_{\text {Sidiat }}, \mathrm{f}_{\text {Pdiat }}, \mathrm{f}_{\text {Ldiat }}\right) \mathrm{X}_{6}+$ bottom $\cdot \mathrm{k}_{\operatorname{minN}} \mathrm{r}_{\text {bent }} \mathrm{f}_{\mathrm{T}} \mathrm{X}_{14} /\left(\mathrm{z}_{\text {max }}-\mathrm{z}_{\text {min }}\right)$

$-\mu_{\max d i n o} \mathrm{rNH} 4_{\text {dino }} \mathrm{f}_{\mathrm{T}} \min \left(\mathrm{f}_{\mathrm{Ndin},}, \mathrm{f}_{\mathrm{Pdino}}, \mathrm{f}_{\text {Ldino }}\right) \mathrm{X}_{7}-\mu_{\max \text { nano }} \mathrm{rNH} 4_{\text {nano }} \mathrm{f}_{\mathrm{T}} \min \left(\mathrm{f}_{\mathrm{Nnano}}, \mathrm{f}_{\mathrm{Pnano}}, \mathrm{f}_{\text {Lnano }}\right) \mathrm{X}_{8}-\mathrm{k}_{\text {nitrif }} \mathrm{X}_{1}$

$+\mathrm{f}_{\mathrm{T}}\left(\mathrm{e}_{\text {microzoo }} \mathrm{X}_{9}+\mathrm{e}_{\text {mesozoo }} \mathrm{X}_{10}\right)$

Nitrate $\mathrm{X}_{2}\left(\mu \mathrm{mol} \mathrm{L}{ }^{-1}\right)$ :

(Equation 2)

$\begin{aligned} \frac{\mathrm{dX}}{\mathrm{dt}} & =\mathrm{k}_{\text {nitrif }} \mathrm{X}_{1}-\mu_{\text {max diat }} \mathrm{rNO} 3_{\text {diat }} \mathrm{f}_{\mathrm{T}} \min \left(\mathrm{f}_{\text {Ndiat }}, \mathrm{f}_{\text {Sidiat }}, \mathrm{f}_{\text {Pdiat }}, \mathrm{f}_{\text {Ldiat }}\right) \mathrm{X}_{6}-\mu_{\max \operatorname{dino}} \mathrm{rNO} 3_{\text {dino }} \mathrm{f}_{\mathrm{T}} \min \left(\mathrm{f}_{\text {Ndino }}, \mathrm{f}_{\text {Pdino }}, \mathrm{f}_{\text {Ldino }}\right) \mathrm{X}_{7} \\ & -\mu_{\text {max nano }} \mathrm{rNO} 3_{\text {nano }} \mathrm{f}_{\mathrm{T}} \min \left(\mathrm{f}_{\text {Nnano }}, \mathrm{f}_{\text {Pnano }}, \mathrm{f}_{\text {Lnano }}\right) \mathrm{X}_{8}\end{aligned}$

Dissolved silicon $\mathrm{X}_{3}\left(\mu \mathrm{mol} \mathrm{L}^{-1}\right)$ :

(Equation 3)

$\frac{\mathrm{dX}_{3}}{\mathrm{dt}}=\mathrm{k}_{\text {diss }} \mathrm{f}_{\mathrm{T}} \mathrm{X}_{12}-\mathrm{r}_{\text {Si: N }} \mu_{\text {max diat }} \mathrm{f}_{\mathrm{T}} \min \left(\mathrm{f}_{\text {Ndiat }}, \mathrm{f}_{\text {Sidiat }}, \mathrm{f}_{\text {Pdiat }}, \mathrm{f}_{\text {Ldiat }}\right) \mathrm{X}_{6}+$ bottom $\cdot \mathrm{k}_{\text {dissol }} \mathrm{r}_{\text {bent }} \mathrm{f}_{\mathrm{T}} \mathrm{X}_{15} /\left(\mathrm{z}_{\text {max }}-\mathrm{z}_{\text {min }}\right)$

Dissolved phosphorus $\mathrm{X}_{4}\left(\mu \mathrm{mol} \mathrm{L}{ }^{-1}\right)$ :

(Equation 4)

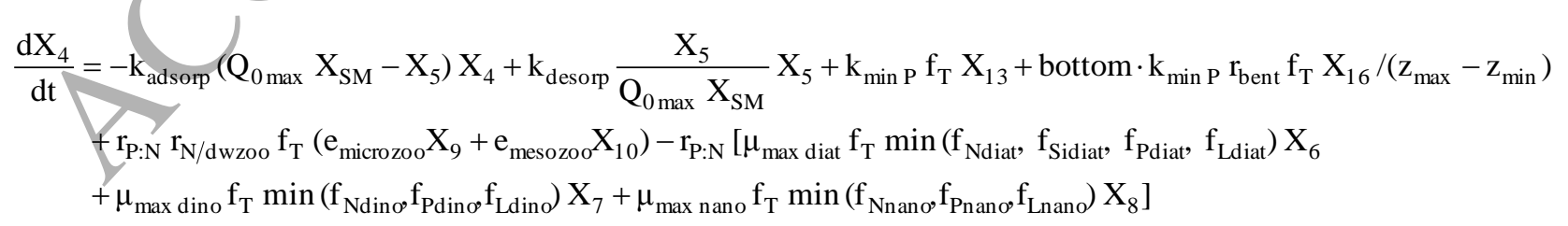

Particulate exchangeable phosphorus $\mathrm{X}_{5}\left(\mu \mathrm{mol} \mathrm{L}{ }^{-1}\right)$ :

(Equation 5)

$\frac{\mathrm{dX}_{5}}{\mathrm{dt}}=\mathrm{k}_{\text {adsorp }}\left(\mathrm{Q}_{0 \max } \mathrm{X}_{\mathrm{SM}}-\mathrm{X}_{5}\right) \mathrm{X}_{4}-\mathrm{k}_{\mathrm{desorp}} \frac{\mathrm{X}_{5}}{\mathrm{Q}_{0 \max } \mathrm{X}_{\mathrm{SM}}} \mathrm{X}_{5}$ 
Diatom nitrogen $\mathrm{X}_{6}\left(\mu \mathrm{mol} \mathrm{L}{ }^{-1}\right)$ :

(Equation 6)

$\frac{\mathrm{dX}_{6}}{\mathrm{dt}}=\mathrm{f}_{\mathrm{T}}\left(\mu_{\text {max diat }} \min \left(\mathrm{f}_{\text {Ndiat }}, \mathrm{f}_{\text {Sidiat }}, \mathrm{f}_{\text {Pdiat }}, \mathrm{f}_{\text {Ldiat }}\right)-\mathrm{m}_{\text {diat }}\right) \mathrm{X}_{6}$

$\frac{-\mu_{\text {max mesozoo }} \mathrm{f}_{\mathrm{T}} \mathrm{X}_{10} \mathrm{r}_{\text {diatmesozoo }} \mathrm{X}_{6}}{\mathrm{r}_{\text {diatmesozoo }} \mathrm{X}_{6}+\mathrm{r}_{\text {dinomesozø }} \mathrm{X}_{7}+\mathrm{r}_{\text {microzoomesozoo }} \mathrm{X}_{9}}\left[1-\exp \left(-\gamma_{\text {mesozoo }}\left(\mathrm{r}_{\text {diatmesozoo }} \mathrm{X}_{6}+\mathrm{r}_{\text {dinomesozø }} \mathrm{X}_{7}+\mathrm{r}_{\text {microzoomesozoo }} \mathrm{X}_{9}-\mathrm{Th}_{\text {mesozoo }}\right)\right)\right]$

$\frac{-\mu_{\operatorname{max~microzoo~}} \mathrm{f}_{\mathrm{T}} \mathrm{X}_{10} \mathrm{r}_{\text {diatmicrozoo }} \mathrm{X}_{6}}{\mathrm{r}_{\text {diatmicrozoo }} \mathrm{X}_{6}+\mathrm{r}_{\text {dinomicrozo }} \mathrm{X}_{7}+\mathrm{r}_{\text {det microzoo }} \mathrm{X}_{9}}\left[\frac{\mathrm{r}_{\text {diatmicrozoo }} \mathrm{X}_{6}+\mathrm{r}_{\text {dinomicro oo }} \mathrm{X}_{7}+\mathrm{r}_{\text {det microzoo }} \mathrm{X}_{9}-\mathrm{Th}_{\text {microzoo }}}{\mathrm{K}_{\text {microzoo }}+\mathrm{r}_{\text {diatmicrozoo }} \mathrm{X}_{6}+\mathrm{r}_{\text {dinomicrooo }} \mathrm{X}_{7}+\mathrm{r}_{\text {det microzoo }} \mathrm{X}_{9}-\mathrm{Th}_{\text {microzoo }}}\right]$

Dinoflagellate nitrogen $\mathrm{X}_{7}\left(\mu \mathrm{mol} \mathrm{L} \mathrm{L}^{-1}\right)$ :

(Equation 7)



Nanoflagellate nitrogen $\mathrm{X}_{8}\left(\mu \mathrm{mol} \mathrm{L} \mathrm{L}^{-1}\right)$ :

(Equation 8)

$\frac{\mathrm{dX}_{8}}{\mathrm{dt}}=\mathrm{f}_{\mathrm{T}}\left(\mu_{\max \text { nano }} \min \left(\mathrm{f}_{\text {Nnano }}, \mathrm{f}_{\text {Pnano }}, \mathrm{f}_{\text {Lnano }}\right)-\mathrm{m}_{\text {nano }}\right) \mathrm{X}_{8}$
$-\mathrm{f}_{\mathrm{T}} \mathrm{r}_{\mathrm{N} / \mathrm{dwzoo}} \frac{\mathrm{r}_{\text {nanomesozø }} \mathrm{X}_{8}}{\mathrm{r}_{\text {nanomesozø }} \mathrm{X}_{8}+\mathrm{r}_{\text {det microzoo }} \mathrm{X}_{11}}$
$\left[1-\exp \left(-\gamma_{\text {microzoo }}\left(\mathrm{r}_{\text {nanomesozo }} \mathrm{X}_{8}+\mathrm{r}_{\text {det microzoo }} \mathrm{X}_{11}-\mathrm{Thr}_{\text {microzoo }}\right)\right)\right] \mu_{\text {max microzoo }} \mathrm{X}_{9}$

Microzooplankton nitrogen $\mathrm{X}_{9}\left(\mu \mathrm{mol} \mathrm{L}^{-1}\right)$ :

(Equation 9)



Mesozooplankton nitrogen $\mathrm{X}_{10}\left(\mu \mathrm{mol} \mathrm{L}{ }^{-1}\right)$ :

(Equation 10)

$\frac{\mathrm{dX}_{10}}{\mathrm{dt}}=\mu_{\text {max mesozoo }} \operatorname{Assf}_{\mathrm{T}} \mathrm{X}_{10}$

$\left[1-\exp \left(-\gamma_{\text {mesozoo }}\left(r_{\text {diatmesozoo }} X_{6}+r_{\text {dinomesozo }} X_{7}+r_{\text {microzoomesozoo }} X_{9}-\mathrm{Th}_{\text {mesozoo }}\right)\right)\right]$

$-\mathrm{e}_{\text {zoo }} \mathrm{f}_{\mathrm{T}} \mathrm{X}_{10}-\mathrm{f}_{\mathrm{T}} \max \left(\mathrm{m} 1_{\text {mesozoo }}, \mathrm{m} 2_{\text {mesozoo }} \mathrm{X}_{10}\right) \mathrm{X}_{10}$

Suspended detrital organic nitrogen $\mathrm{X}_{11}\left(\mu \mathrm{mol} \mathrm{L}{ }^{-1}\right)$ :

(Equation 11)

$\frac{d X_{11}}{d t}=m_{\text {diat }} f_{T} X_{6}+m_{\text {dino }} f_{T} X_{7}+m_{\text {nano }} f_{T} X_{8}-k_{\text {min N }} f_{T} X_{11}+$ bottom $\cdot\left[r_{\text {erod }} X_{14}-w_{\text {dep }} X_{11}\right] /\left(z_{\text {max }}-z_{\text {min }}\right)$

$+\mathrm{f}_{\mathrm{T}} \max \left(\mathrm{m}_{\min z o o}, \mathrm{~m}_{\text {fzoo }} \mathrm{X}_{9}\right) \mathrm{X}_{9}+(1-$ Ass $) \mathrm{f}_{\mathrm{T}}$

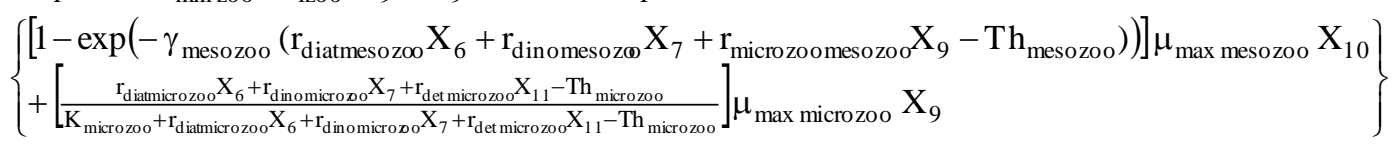




$$
\begin{aligned}
& \frac{\mathrm{dX}_{12}}{\mathrm{dt}}=\mathrm{m}_{\text {diat }} \mathrm{f}_{\mathrm{T}} \mathrm{r}_{\mathrm{Si:N}} \mathrm{X}_{6}-\mathrm{k}_{\mathrm{dissol}} \mathrm{f}_{\mathrm{T}} \mathrm{X}_{12}+\mathrm{f}_{\mathrm{T}} \mathrm{r}_{\mathrm{Si}: \mathrm{N}} \mathrm{r}_{\mathrm{N}: \mathrm{dwzoo}}+\text { bottom } \cdot\left[\mathrm{r}_{\text {erod }} \mathrm{r}_{\mathrm{Si}: \mathrm{N}} \mathrm{X}_{15}-\mathrm{w}_{\mathrm{dep}} \mathrm{X}_{12}\right] /\left(\mathrm{z}_{\max }-\mathrm{z}_{\text {min }}\right) \\
& +\left[1-\exp \left(-\gamma_{\text {mesozoo }}\left(r_{\text {diatmesozoo }} \mathrm{X}_{6}+\mathrm{r}_{\text {dinomesozø }} \mathrm{X}_{7}+\mathrm{r}_{\text {microzoomesozoo }} \mathrm{X}_{9}-\mathrm{Th}_{\text {mesozoo }}\right)\right)\right] \mu_{\text {max mesozoo }} \mathrm{r}_{\text {Si:N }} \mathrm{X}_{10} \\
& +\left[\frac{\mathrm{r}_{\text {diatmicrozoo }} \mathrm{X}_{6}+\mathrm{r}_{\text {dinomicrooo }} \mathrm{X}_{7}+\mathrm{r}_{\text {det microzoo }} \mathrm{X}_{11}-\mathrm{Th}_{\text {microzoo }}}{\mathrm{K}_{\text {microzoo }}+\mathrm{r}_{\text {diatricrozoo }} \mathrm{X}_{6}+\mathrm{r}_{\text {dinomicroo o }} \mathrm{X}_{7}+\mathrm{r}_{\text {det micro zoo }} \mathrm{X}_{11}-\mathrm{Th}_{\text {microzoo }}}\right] \mu_{\text {max microzoo }} \mathrm{r}_{\mathrm{Si:N}} \mathrm{X}_{9}
\end{aligned}
$$

$$
\begin{aligned}
& \frac{\mathrm{dX} \mathrm{X}_{13}}{\mathrm{dt}}=-\mathrm{k}_{\min \mathrm{P}} \mathrm{f}_{\mathrm{T}} \mathrm{X}_{13}+\mathrm{r}_{\mathrm{P}: \mathrm{N}} \mathrm{f}_{\mathrm{T}}\left(\mathrm{m}_{\mathrm{diat}} \mathrm{X}_{6}+\mathrm{m}_{\mathrm{dino}} \mathrm{X}_{7}+\mathrm{m}_{\text {nano }} \mathrm{X}_{8}\right)+\text { bottom } \cdot\left[\mathrm{r}_{\text {erod }} \mathrm{r}_{\mathrm{P}: \mathrm{N}} \mathrm{X}_{16}-\mathrm{w}_{\mathrm{dep}} \mathrm{X}_{13}\right] /\left(\mathrm{z}_{\max }-\mathrm{z}_{\text {min }}\right) \\
& +\mathrm{f}_{\mathrm{T}} \mathrm{r}_{\mathrm{P}: \mathrm{N}}\left[\mathrm{m}_{\text {microzoo }} \mathrm{X}_{9}+\max \left(\mathrm{ml}_{\text {mesozoo }}, \mathrm{m} 2_{\text {mesozoo }} \mathrm{X}_{10}\right) \mathrm{X}_{10}\right]+(1-\mathrm{Ass}) \mathrm{f}_{\mathrm{T}} \mathrm{r}_{\mathrm{P}: \mathrm{N}} \\
& \left\{\begin{array}{l}
{\left[1-\exp \left(-\gamma_{\text {mesozoo }}\left(\mathrm{r}_{\text {diatmesozoo }} \mathrm{X}_{6}+\mathrm{r}_{\text {dinomesozø }} \mathrm{X}_{7}+\mathrm{r}_{\text {microzoomesozoo }} \mathrm{X}_{9}-\mathrm{Th}_{\text {mesozoo }}\right)\right)\right] \mu_{\text {max mesozoo }} \mathrm{X}_{10}} \\
+\left[\frac{\mathrm{r}_{\text {diammicrozoo }} \mathrm{X}_{6}+\mathrm{r}_{\text {dinomicrooo }} \mathrm{X}_{7}+\mathrm{r}_{\text {det microzoo }} \mathrm{X}_{11}-\mathrm{Th}_{\text {microzoo }}}{\mathrm{K}_{\text {microzoo }}+\mathrm{r}_{\text {diatmicrozoo }} \mathrm{X}_{6}+\mathrm{r}_{\text {dinomicro oo }} \mathrm{X}_{7}+\mathrm{r}_{\text {det microzoo }} \mathrm{X}_{11}-\mathrm{Th}_{\text {microzoo }}}\right] \mu_{\text {max microzoo }} \mathrm{X}_{9}
\end{array}\right\}
\end{aligned}
$$

Benthic detrital organic nitrogen $\mathrm{X}_{14}\left(\mathrm{mmol} \mathrm{m}^{-2}\right)$ :

(Equation 14)

$$
\frac{\mathrm{dX} \mathrm{X}_{14}}{\mathrm{dt}}=\text { bottom } \cdot\left[\mathrm{w}_{\mathrm{dep}} \mathrm{X}_{11}-\left(\mathrm{r}_{\text {erod }}+\mathrm{k}_{\text {min N }} \mathrm{r}_{\text {bent }} \mathrm{f}_{\mathrm{T}}+\mathrm{r}_{\text {burial }}\right) \mathrm{X}_{14}+\mathrm{r}_{\text {filt }}\left(\mathrm{X}_{6}+\mathrm{X}_{7}+\mathrm{X}_{8}\right)\right]
$$

Benthic detrital biogenic silicon $\mathrm{X}_{15}\left(\mathrm{mmol} \mathrm{m}^{-2}\right)$ :

(Equation 15)

$$
\frac{\mathrm{dX}_{15}}{\mathrm{dt}}=\text { bottom } \cdot\left[\mathrm{w}_{\text {dep }} \mathrm{X}_{12}-\left(\mathrm{r}_{\text {erod }} \mathrm{r}_{\mathrm{Si:N}}+\mathrm{k}_{\text {dissol }} \hat{\mathrm{r}}_{\text {bent }} \mathrm{f}_{\mathrm{T}}+\mathrm{r}_{\text {burial }}\right) \mathrm{X}_{15}+\mathrm{r}_{\text {filt }} \mathrm{r}_{\mathrm{Si:N}} \mathrm{X}_{6}\right]
$$

Benthic detrital organic phosphorus $\mathrm{X}_{16}\left(\mathrm{mmol} \mathrm{m}^{-2}\right)$ :

(Equation 16)

$$
\frac{\mathrm{dX}}{16}=\text { bottom } \cdot\left[\mathrm{w}_{\text {dep }} \mathrm{X}_{13}-\left(\mathrm{r}_{\text {erod }} \mathrm{r}_{\mathrm{P}: \mathrm{N}}+\mathrm{k}_{\text {min P }} \mathrm{r}_{\text {bent }} \mathrm{f}_{\mathrm{T}}+\mathrm{r}_{\text {burial }}\right) \mathrm{X}_{16}+\mathrm{r}_{\text {filt }} \mathrm{r}_{\mathrm{P}: \mathrm{N}}\left(\mathrm{X}_{6}+\mathrm{X}_{7}+\mathrm{X}_{8}\right)\right]
$$

Dissolved oxygen $\mathrm{X}_{17}\left(\mathrm{mg} \mathrm{L}^{-1}\right)$ :

(Equation 17)

$$
\begin{aligned}
& \frac{d X_{17}}{d t}=f_{T}\left[r _ { \text { O2 } j N _ { - } \text { ana } } \left[\mu_{\max \text { diat }} \min \left(f_{\text {Ndiat }}, f_{\text {Sidiat }}, f_{\text {Pdiat }}, f_{\text {Ldiat }}\right) X_{6}+\mu_{\max \text { dino }} \min \left(f_{\text {Ndino }}, f_{\text {Pdino }}, f_{\text {Ldino }}\right) X_{7}\right.\right. \\
& \left.+\mu_{\text {max nano }} \min \left(f_{\text {Nnano }}, f_{\text {Pnano }}, f_{\text {Lnano }}\right) X_{8}\right]-r_{\text {O2:N_cata }}\left[r_{\text {respphy }}\left(\left(1-f_{\text {Ldiat }}\right) X_{6}+\left(1-f_{\text {Ldino }}\right) X_{7}+\left(1-f_{\text {Lnano }}\right) X_{8}\right)\right. \\
& \left.\left.-k_{\min N} X_{11}-k_{\text {nitrif }} X_{1}-e_{\text {zoo }}\left(X_{9}+X_{10}\right)\right]\right]
\end{aligned}
$$


Appendix B: Driving functions used in the equations detailed in Appendix A

bottom $=1$ for the bottom water layer, $=0$ for other water layers

$\mathrm{u}$ : bottom current velocity $\left(\mathrm{m} \mathrm{s}^{-1}\right)$

$\mathrm{T}$ : temperature $\left({ }^{\circ} \mathrm{C}\right)$

$\mathrm{I}$ : PAR light intensity at sea surface $\left(\mathrm{W} \mathrm{m}^{-2}\right)$

$\mathrm{SM}$ : suspended matter $\left(\mathrm{mg} \mathrm{L}^{-1}\right)$

Nut : $\left[\mathrm{PO}_{4}\right]$ or $\left[\mathrm{Si}(\mathrm{OH})_{4}\right]\left(\mu \mathrm{mol} \mathrm{L}^{-1}\right)$

extinction coefficient: $\mathrm{k}=\mathrm{k}_{\mathrm{DM}}+k_{S M} S M+k_{C 1}\left[\left(X_{6}+X_{7}+X_{8}\right) / r_{N / \text { chloro }}\right]^{k_{C 2}}$

Temperature effect: $\mathrm{f}_{\mathrm{T}}=\exp (a T)$

Light limitation (Smith equation averaged over the water layer):

$\mathrm{f}_{\mathrm{L}}=\frac{1}{k\left(z_{\max }-z_{\min }\right)}\left[\ln \left[\frac{\frac{I}{I_{k p h y}} \exp \left(-k z_{\min }\right)+\sqrt{1+\left(\frac{I}{I_{k p h y}} \exp \left(-k z_{\min }\right)\right)^{2}}}{\frac{I}{I_{k p h y}} \exp \left(-k z_{\max }\right)+\sqrt{1+\left(\frac{I}{I_{k p h y}} \exp \left(-k z_{\text {max }}\right)\right)^{2}}}\right]\right.$

Nutrient limiting effect for phosphorus or silicon on phytoplankton phy: $\mathrm{f}_{\text {Nutphy }}=\frac{\text { Nut }}{\text { Nut }+K_{\text {Nutphy }}}$

Nutrient limiting effect for nitrogen on phytoplankton phy: $\mathrm{f}_{\mathrm{N}}=\frac{X_{1} / K_{N H 4 p h y}+X_{2} / K_{N O 3 p h y}}{1+X_{1} / K_{N H 4 p h y}+X_{2} / K_{N O 3 \text { phy }}}$

Deposition velocity : $\mathrm{w}_{\mathrm{dep}}=w_{s} \max \left[0.0,1.0-\left(\frac{w}{u_{\text {critdep }}}\right)^{2}\right]$

Erosion rate $: r_{\text {erod }}=r_{\text {erodref }} \max \left[0.0,\left(\frac{u}{u_{\text {criterod }}}\right)^{2}-1.0\right]$

ratio of ammonia in the total nitrogen uptake of phy toplankon phy:

$\mathrm{rNH}_{\text {phy }}=\frac{\mathrm{X}_{1}}{\mathrm{X}_{1}+\mathrm{K}_{\mathrm{NH} 4 \mathrm{phy}}+\mathrm{X}_{2} \frac{\mathrm{K}_{\mathrm{NH} 4 \mathrm{phy}}}{\mathrm{K}_{\mathrm{NO} 3 \text { phy }}}}$

ratio of nitrate in the total nitrogen uptake of phytoplanlton phy:

$\mathrm{rNO}_{\text {phy }}=\frac{\mathrm{X}_{2}}{\mathrm{X}_{2}+\mathrm{K}_{\mathrm{NO} 3 \mathrm{phy}}+\mathrm{X}_{2} \frac{\mathrm{K}_{\mathrm{NO} 3 \mathrm{phy}}}{\mathrm{K}_{\mathrm{NH} 4 \mathrm{phy}}}}$

Benthic grazing at julian day jd performed by filter-feeders upon phytoplankton phy in a bottom water layer having a thickness $\Delta \mathrm{z}$ :

$g_{\text {benth }}($ phy,jd, $\Delta \mathrm{z})=\left[0.03+0.07\left[\frac{1+\sin [2 \pi(\mathrm{jd}-125) / 365]}{2}\right]\right] \mathrm{phy} / \Delta \mathrm{z}$ 